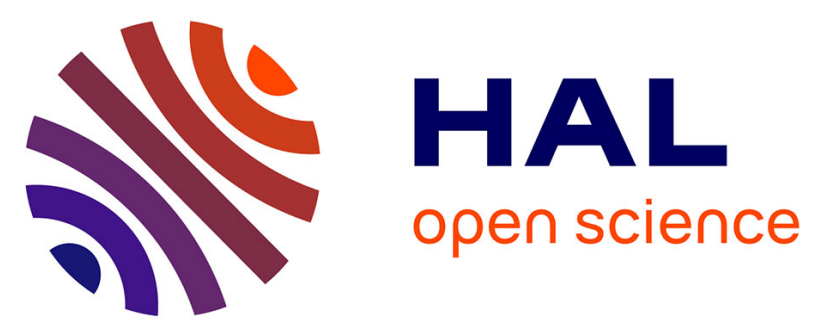

\title{
Un dépôt sous-marin de lames polies néolithiques en jadéitite et sillimanite, et un ouvrage de stèles submergé sur la plage dite du Petit Rohu près Saint-Pierre-Quiberon (Morbihan)
}

Serge Cassen, Christine Boujot, Michel Errera, David Meunier, Yvan Pailler, Pierre Pétrequin, Dominique Marguerie, Elisabeth Veyrat, Emmanuelle Vigier, Sandy Poirier, et al.

\section{- To cite this version:}

Serge Cassen, Christine Boujot, Michel Errera, David Meunier, Yvan Pailler, et al.. Un dépôt sousmarin de lames polies néolithiques en jadéitite et sillimanite, et un ouvrage de stèles submergé sur la plage dite du Petit Rohu près Saint-Pierre-Quiberon (Morbihan). Bulletin de la Société préhistorique française, 2010, 107 (1), pp.53-84. hal-02379023

\section{HAL Id: hal-02379023 \\ https://hal.science/hal-02379023}

Submitted on 18 Mar 2020

HAL is a multi-disciplinary open access archive for the deposit and dissemination of scientific research documents, whether they are published or not. The documents may come from teaching and research institutions in France or abroad, or from public or private research centers.
L'archive ouverte pluridisciplinaire HAL, est destinée au dépôt et à la diffusion de documents scientifiques de niveau recherche, publiés ou non, émanant des établissements d'enseignement et de recherche français ou étrangers, des laboratoires publics ou privés. 
Serge CASSEN, Christine BOUJOT, Michel ERRERA, David MENIER, Yvan PAILLER, Pierre PÉTREQUIN, Dominique MARGUERIE, Elisabeth VEYRAT, Emmanuelle VIGIER,

Sandy POIRIER,

Charles DAGNEAU,

Denis DEGEZ, Thierry LORHO,

Hervé NEVEU-DEROTRIE,

Christian OBELTZ,

Florent SCALLIET et Yohann SPARFEL
Un dépôt sous-marin de lames polies néolithiques en jadéitite et sillimanite, et un ouvrage de stèles submergé sur la plage dite du Petit Rohu près Saint-Pierre-Quiberon (Morbihan)

\begin{abstract}
Résumé
En août 2007, des vacanciers découvrent deux couples de lames de haches polies plantées dans une vase argileuse sur l'estran de Porh Fetan, dit du Petit Rohu, qu'ils signalent au service régional de l'Archéologie de Bretagne, ainsi qu'au musée de Carnac. La morphologie de ces lames et le matériau employé permettent d'emblée de les identifier aux spécimens en roches alpines largement documentés dans la région. Une autorisation est alors sollicitée par le SRA (Rennes) pour le Laboratoire de recherches archéologiques (UMR 6566, Nantes) auprès du DRASSM (Marseille) en vue d'une opération d'archéologie sous-marine et terrestre. Une première mission menée à l'occasion des grandes marées du 28 septembre 2007 ne permet pas de ramener une nouvelle récolte d'objets, mais provoque la découverte sur site d'un ouvrage de stèles submergé, structure formant au moins un alignement de dalles chutées (un seul bloc de chant encore en place) qui sont aussitôt relevées en plan, complétées lors d'une seconde mission aux grandes marées du 27 octobre. Une troisième mission décidée aux dernières marées de l'année, le 26 novembre, conduit à la découverte d'une nouvelle lame de hache, mais en fibrolite et au contact d'une stèle. Des sols tourbeux, visibles par intermittence depuis plusieurs années sous le sable marin, sont progressivement dégagés puis détruits par l'océan sur une plage de plus en plus amaigrie au cours du temps; ces sols conservent des traces de labours, parfois croisés, et des empreintes d'Ongulés. Le contexte environnemental permet d'avancer que les lames de haches furent enfouies dans un milieu marécageux développé derrière un cordon dunaire, au pied d'un affleurement rocheux remarquable, le rivage devant être éloigné de quelque $500 \mathrm{~m}$ au milieu du $V^{e}$ millénaire av. J.-C., date relative proposée pour le rassemblement de ces objets. L'ouvrage de stèles et l'emplacement du dépôt sont actuellement recouverts par plus de $5 \mathrm{~m}$ d'eau. Ces vestiges architecturaux rejoignent la liste récemment établie des découvertes sous-marines similaires faites en baie de Quiberon, ria d'Etel et
\end{abstract}


golfe du Morbihan depuis 1998. Les analyses en spectroradiométrie confirment l'origine alpine des pierres (jadéitite) et l'identité de la rochemère pour au moins 3 individus; l'observation des surfaces témoigne du fort investissement en termes de travail de polissage (poli «miroir» conservé par plaques) qui a entièrement transformé les lames utilitaires de départ.

\begin{abstract}
In August 2007, holidaymakers discovered two pairs of polished axeheads that had been set vertically in clayey silt on the beach of Porh Fetan, at a place called Petit Rohu. They reported their find to the Regional Archaeology Service of Brittany and to the Carnac Museum. The shape and material of these axeheads allowed them to be identified straightaway as being of Alpine origin, in common with a number of axeheads found in the region. Permission was obtained from the DRASSM (Marseille) for the Laboratory of Archaeological Research (UMR 6566, Nantes), together with the SRA (in Rennes), to undertake archaeological fieldwork, both on land in the vicinity of the findspot, and under water. Initial fieldwork, carried out during the spring tide on 28th September 2007, produced no further artefacts but did produce evidence for a submerged alignment of stelae (lying stones or fallen menhirs), of which only one was still standing; an initial plan of this structure was made at that point, and completed during the next investigation, during the spring tide on 27th October. A third investigation, carried out during the last spring tide of the year on 26th November, led to the discovery of a fifth axehead, this time made of fibrolite, found resting against one of the lying stones. Peaty soils had been intermittently observed over many years, buried beneath marine sand; these are being progressively eroded away by the force of the sea, as their sand cover becomes thinner. Traces of cultivation (criss-crossing each other in some areas) and of ungulate hoof-prints have been conserved on the surface of these soils. This palaeo-environmental context allows us to argue that the axeheads had been deposited in a marshy environment that had developed behind a dune system, at the foot of a remarkable stone outcrop. Rises in sea level since the mid-fifth millennium BC - the likely date at which the axeheads were deposited - mean that the shore has advanced by some 500 metres since then. Today, the findspot of the stone alignment and axehead deposit lies beneath 5 metres of sea. These architectural vestiges join the list of recent discoveries (since 1998) of submerged monuments in the Bay of Quiberon, the Etel estuary and the Gulf of Morbihan. Initial spectroradiometric analysis of the two pairs of axeheads has confirmed that they are of jadeitite, originating in the Italian Alps. Indeed, at least three of the axeheads can be related to a specific block of jadeitite. Their surface finish attests to a considerable investment of time in order to achieve their mirrorlike polish (which survives over part of their surfaces). This underlines the fact that these were not utilitarian axeheads, but instead were very special and precious artefacts ${ }^{1}$.
\end{abstract}

À l'été 2007, sur la plage du Petit Rohu de la presqu'̂̂le de Quiberon en Morbihan, la découverte fortuite de 4 lames de haches polies aux couleurs, formes et polis extraordinaires ne pouvaient que fasciner le regard et stimuler l'imaginaire des découvreurs (Cassen et al., 2008). On ne saurait encore trop chaleureusement remercier Sonia Hoba (Pierrefitte, France) et Adam MacHale (Malvern, Angleterre) d'avoir aussi promptement jugé bon de faire connaître leur découverte en transmettant ces objets au milieu scientifique et au public ${ }^{2}$.

Le site archéologique est étendu sur le domaine public maritime de l'Etat (fig. 1), au bas de la plage dite du Petit Rohu, lieu-dit Porh Fetan, en limite des communes de Saint-Pierre-Quiberon et Quiberon (Morbihan). En réalité, le Petit Rohu n'est pas un toponyme nautique de la presqu'île de Quiberon (Bernier, 1956, p. 6). Si le Beg Rohu (pointe de la Roche) est bien identifié au sud de l'anse (ou crique) et platier de Kerbougnec (Kerbourgnec, Kerbonnec), il est suivi de «la crique du Porh Fetan» (port de [la] Fontaine) dans l'enquête de G. Bernier, bien située sur la carte marine du SHOM $\left(\mathrm{n}^{\circ} 7141,1995\right)$ mais, curieusement, en lieu et place du Petit Rohu imprimé sur la carte de l'IGN (0821 OT) au 1/25000 (fig. 2). Le Porh Fetan est la juste dénomination environnementale, car nous sommes 

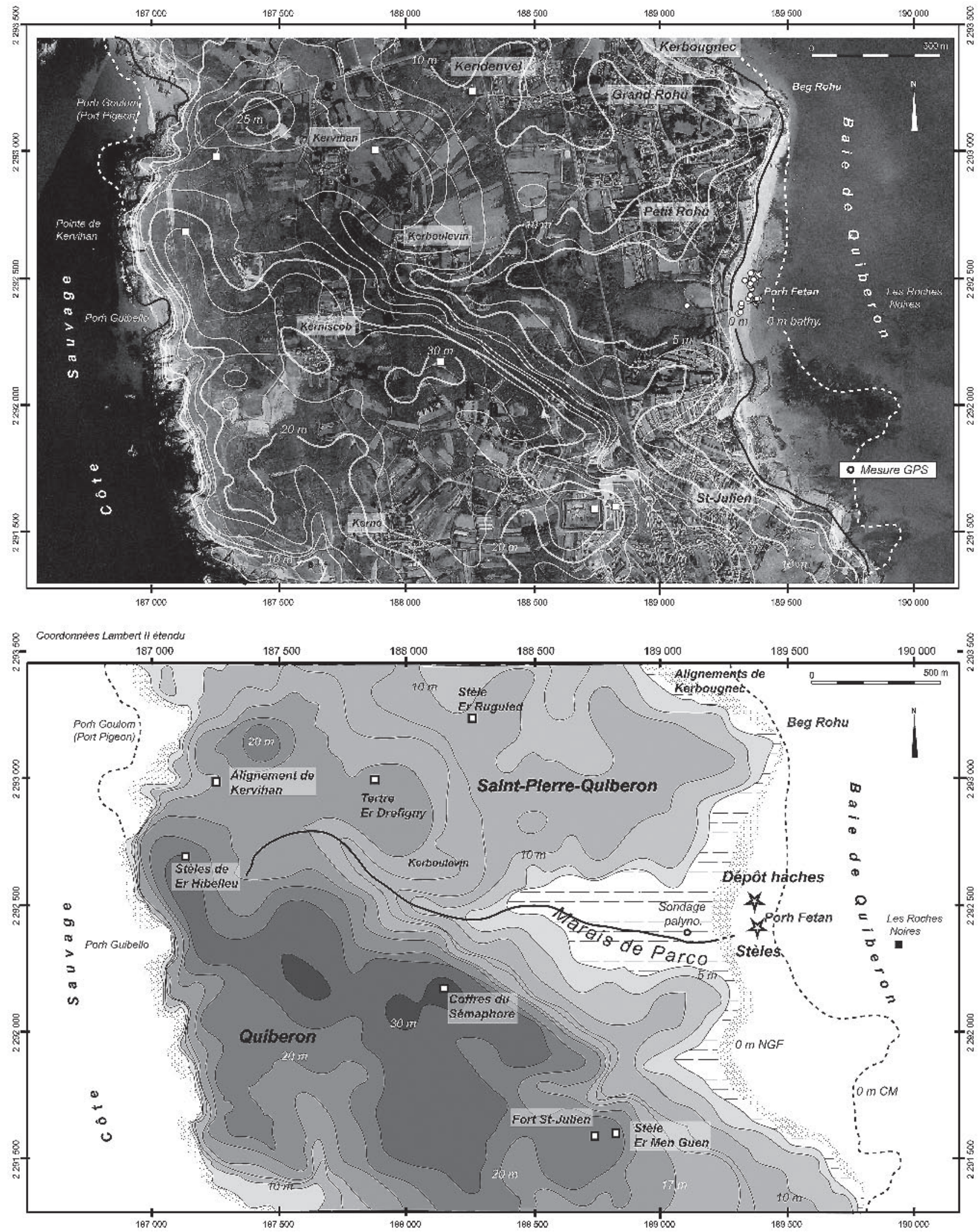

Fig. 1 - Vallée du Parco : localisation du gisement, topographie et distribution des principaux sites archéologiques mentionnés dans le texte (DAO S. Cassen, F. Scaliet; ortho-littorale 2000 - IGN fonds raster).

Fig. 1 - Parco Valley: location of the site, topography and distribution of the main archaeological sites mentioned in the text (CAD S. Cassen, F. Scaliet; ortho-photo IGN raster). 
exactement au débouché du long talweg transversal débutant vers la Côte sauvage entre Porh Goulom (port [du] Pigeon) et la pointe de Kervihan, et se terminant ici, avant les Pierres Noires; la vallée sépare la presqu'île en deux et forme limite communale entre Saint-Pierre-Quiberon et Quiberon; d'où cette arrivée continuelle d'eau douce, en avant du cordon dunaire, un phénomène naturel qui a déterminé le nom. En arrière de ce cordon protecteur, le marais de Parco est le toponyme adopté par l'IGN; il est distinct de la rue

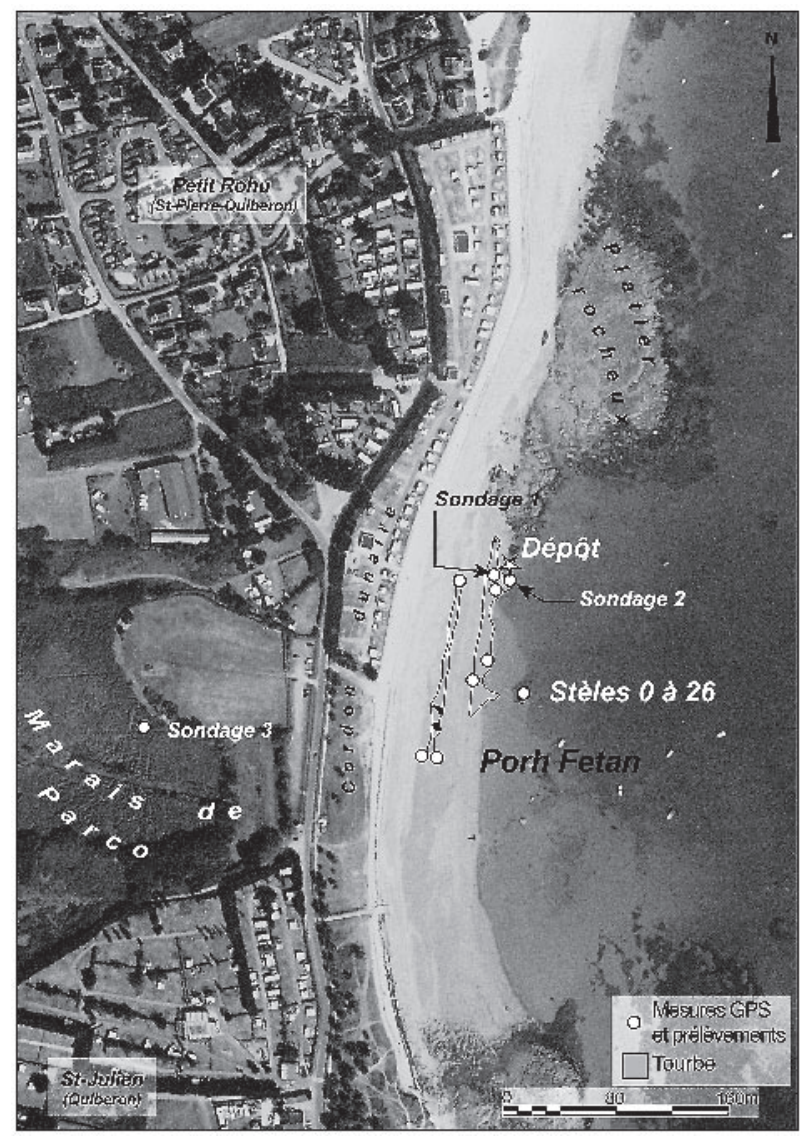

Fig. 2 - Porh Fetan : position des repères GPS au contact des tourbes, du dépôt de haches et de l'ouvrage de stèles (DAO S. Cassen, T. Lorho; ortho-littorale 2000; IGN fonds raster).

Fig. 2 - Porh Fetan: position of GPS reference marks in contact with the peats, the axehead deposit and the construction of stelae (CAD S. Cassen, T. Lorho; IGN raster).
Pargo longeant la plage et qui a servi à désigner le sondage palynologique mené à proximité (Gaudin, $2004)^{3}$, source de confusion.

Les coordonnées principales du gisement s'établissent comme suit (tabl. 1).

À propos des altitudes données dans ce tableau, rappelons qu'en France on distingue le «zéro des topographes », ou «0 NGF» (nivellement général de la France) qui sert pour les nivellements terrestres, et le « zéro des hydrographes », ou «0 CM» (cartes marines, ou encore «bathymétrique») qui sert pour les mesures de profondeur. Le zéro topographique est séparé du zéro hydrographique par une hauteur voisine de la moitié du marnage maximal local : il se trouve par exemple à $3 \mathrm{~m}$ plus haut que lui sur les côtes du golfe de Gascogne, $15 \mathrm{~cm}$ sur les côtes méditerranéennes et $7,50 \mathrm{~m}$ dans le fond de la baie du Mont-SaintMichel...

Cet article se propose donc de mettre l'accent sur l'observation et l'analyse des lames polies recueillies, mais sans développer les résultats plus techniques (signatures comparées des spectres, résidus en surface, extraction par choc thermique attesté) reportés à une publication ultérieure au sein du programme qui leur est consacré. La question relative à l'ouvrage de stèles est trop complexe pour être abordée en quelques lignes sans risquer de tomber dans l'ellipse et la conjecture; on se contentera dès lors de souligner l'articulation remarquée avec ces haches. Avant de faire le point sur les contextes archéologiques et environnementaux présidant à l'analyse descriptive générale des vestiges, revenons sur la chronologie des faits et l'ordre d'avancement des travaux de diagnostic et d'expertise ${ }^{4}$.

\section{CHRONOLOGIE DES DÉCOUVERTES ET DES INTERVENTIONS}

Les objets ont été découverts le 2 août 2007 sur l'estran en début de marée montante, par coefficient de 95. Il n'émergeait à ce moment-là, du substrat sabloargileux et sous $20 \mathrm{~cm}$ d'eau, que l'extrémité de deux tranchants placés côte à côte, face contre face, à hauteur égale. Leur dégagement à l'aide d'une baguette de bois révéla deux grandes lames polies en roche verte plantées dans le sous-sol marin. En inspectant les

\begin{tabular}{|c|c|c|c|c|c|c|}
\hline \multirow{2}{*}{ Désignation } & \multirow{2}{*}{ Type } & \multicolumn{2}{|c|}{ Coordonnées Lambert II } & \multicolumn{2}{|c|}{ Coordonnées WGS84 } & \multirow{2}{*}{$\begin{array}{c}\text { Altitude } \\
\text { NGF }\end{array}$} \\
\hline & & $\mathrm{X}$ & $\mathbf{Y}$ & Longitude & Latitude & \\
\hline Dépôt haches & Point & 189375 & 2292495 & $-3^{\circ} 07^{\prime} 06,584^{\prime \prime}$ & $47^{\circ} 30^{\prime} 13,4654^{\prime \prime}$ & $-3,39$ \\
\hline Sondage tarière 1 & Point & 189360 & 2292490 & $-3^{\circ} 07^{\prime} 07,279^{\prime \prime}$ & $47^{\circ} 30^{\prime} 13,2702^{\prime \prime}$ & $-2,912$ \\
\hline Sondage tarière 2 & Point & 189369 & 2292487 & $-3^{\circ} 07^{\prime} 06,839^{\prime \prime}$ & $47^{\circ} 30^{\prime} 13,1935^{\prime \prime}$ & $-3,317$ \\
\hline Sondage pallyno. & Point & 189103 & 2292382 & - 307'19,172"' & $47^{\circ} 30^{\prime} 09,2041^{\prime \prime}$ & 0,52 \\
\hline \multirow{2}{*}{ Tourbière ouest } & Coin SO & 189310,47 & 2292358,81 & $-3^{\circ} 07^{\prime} 09,228^{\prime \prime}$ & $47^{\circ} 30^{\prime} 08,9262^{\prime \prime}$ & 0,076 \\
\hline & Coin NE & 189336,13 & 2292486,44 & $-3^{\circ} 07^{\prime} 08,409^{\prime \prime}$ & $47^{\circ} 30^{\prime} 13,0871^{\prime \prime}$ & $-0,332$ \\
\hline \multirow{2}{*}{ Tourbière est } & Coin SO & 189344,13 & 2292416,13 & $-3^{\circ} 07^{\prime} 07,786^{\prime \prime}$ & $47^{\circ} 30^{\prime} 10,8438^{\prime \prime}$ & $-2,216$ \\
\hline & Coin NE & 189363,79 & 2292513,77 & $-3^{\circ} 07^{\prime} 07,212^{\prime \prime}$ & $47^{\circ} 30^{\prime} 14,0199^{\prime \prime}$ & $-2,748$ \\
\hline \multirow{2}{*}{ Alignement } & Coin SO & 189375,12 & 2292399,13 & - 3॰07’06,222"' & $47^{\circ} 30^{\prime} 10,3643^{\prime \prime}$ & $-3,563$ \\
\hline & Coin NE & 189386,45 & 2292413,13 & $-3^{\circ} 07^{\prime} 05,784^{\prime \prime}$ & $47^{\circ} 30^{\prime} 10,8413^{\prime \prime}$ & $-2,791$ \\
\hline
\end{tabular}

Tabl. 1 - Positionnement Lambert II et WGS84 des principaux repères du site Parco/Porh Fetan, et altimétrie NGF.

Tabl. 1 - Lambert II and WGS84 positioning of the principal reference marks of the Parco/Porh Fetan site, and NGF altimetry. 
abords immédiats, A. MacHale mit au jour, à $20-25 \mathrm{~cm}$ vers le sud, une autre paire de lames polies dégagées dans des conditions similaires, tranchants dirigés vers le haut, là encore affleurant à hauteur égale; des repères seront pris pour retrouver l'emplacement («paire nord» ou $\mathrm{n}^{\circ} 1$ et «paire sud» ou n ${ }^{\circ} 2$ distingueront à l'avenir ces deux couples).

Étant donné la situation du site sur l'estran face à un camping très prisé et dans la zone de baignade de ce dernier, une opération de surveillance et de repérage discret a donc été souhaitée par le SRA afin de rechercher, de repérer et de relever les indices susceptibles de révéler la nature du site et de délimiter son étendue, en vue de préparer dans les meilleures conditions une éventuelle opération de sauvetage urgent. Le 28 août, aidée par une marée de coefficient 95 , une opération de reconnaissance des lieux permet de remarquer à l'endroit signalé de la découverte un ensemble de blocs désorganisés. Début septembre, le SRA et le DRASSM sollicitent S. Cassen (CNRS) afin qu'il coordonne une opération de surveillance du site et d'identification du contexte. Une expertise terrestre et sous-marine est programmée sur le site le 28 septembre en raison des grandes marées d'équinoxe de coefficient 112.

Les objectifs relatifs à cette première opération ${ }^{5}$ sont arrêtés et adressés aux différents partenaires sollicités afin :

Montage panoramique 1 : au premier plan, la couche de tourbe; à gauche f'affleurement rocheux (27 novembre 2007, coef. $99 / 100\}$

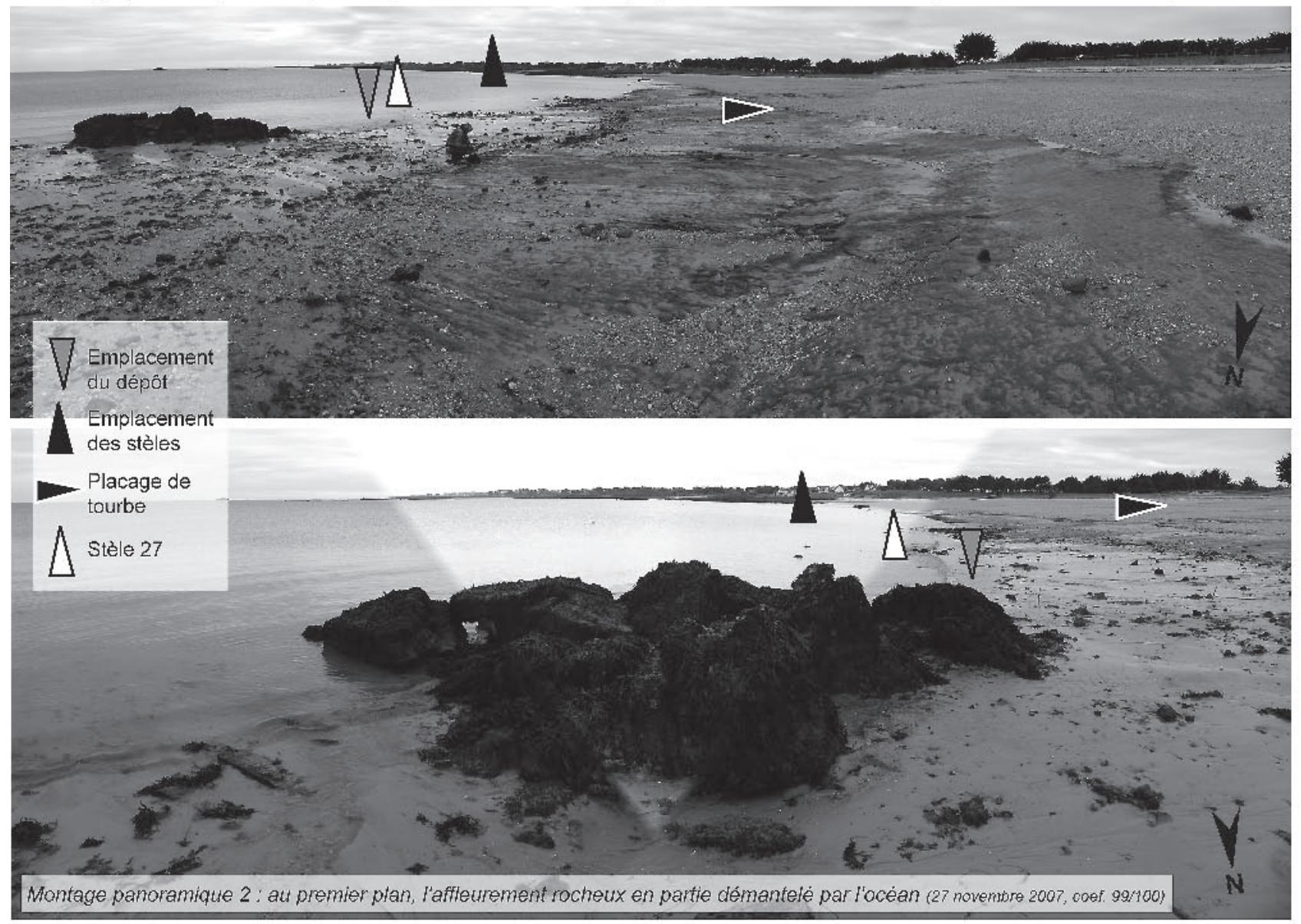

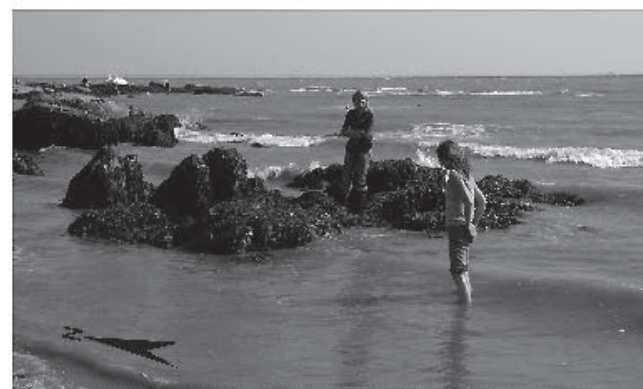

Les dalles verticales de l'affleurement; la personne a droite est debout a l'emplacement oul dépôt ( 8 aoot, coef. 95 )
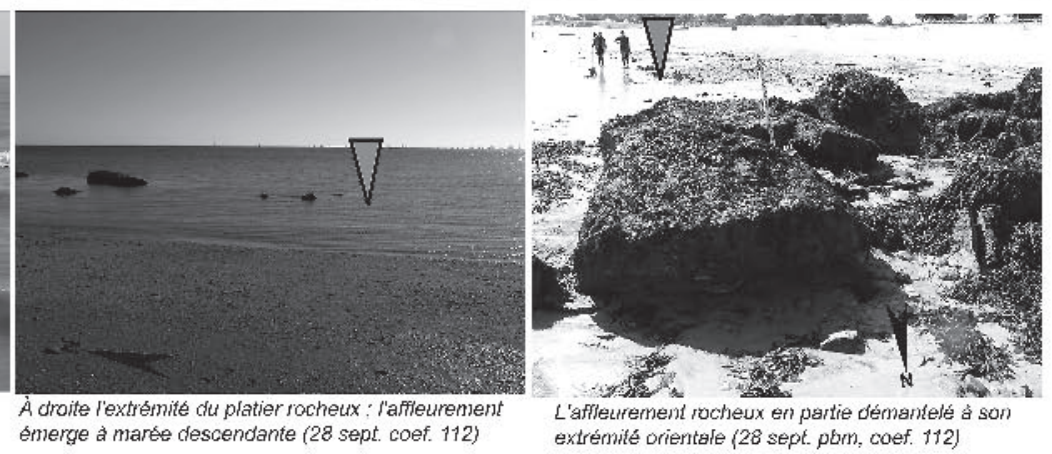

Fig. 3 - Vue d'ensemble du secteur du dépôt de haches par fort coefficient de marée (clichés S. Cassen et P.-A. Besombes).

Fig. 3 - Overall picture of the axehead deposit sector, spring tide (photos S. Cassen and P.-A. Besombes). 


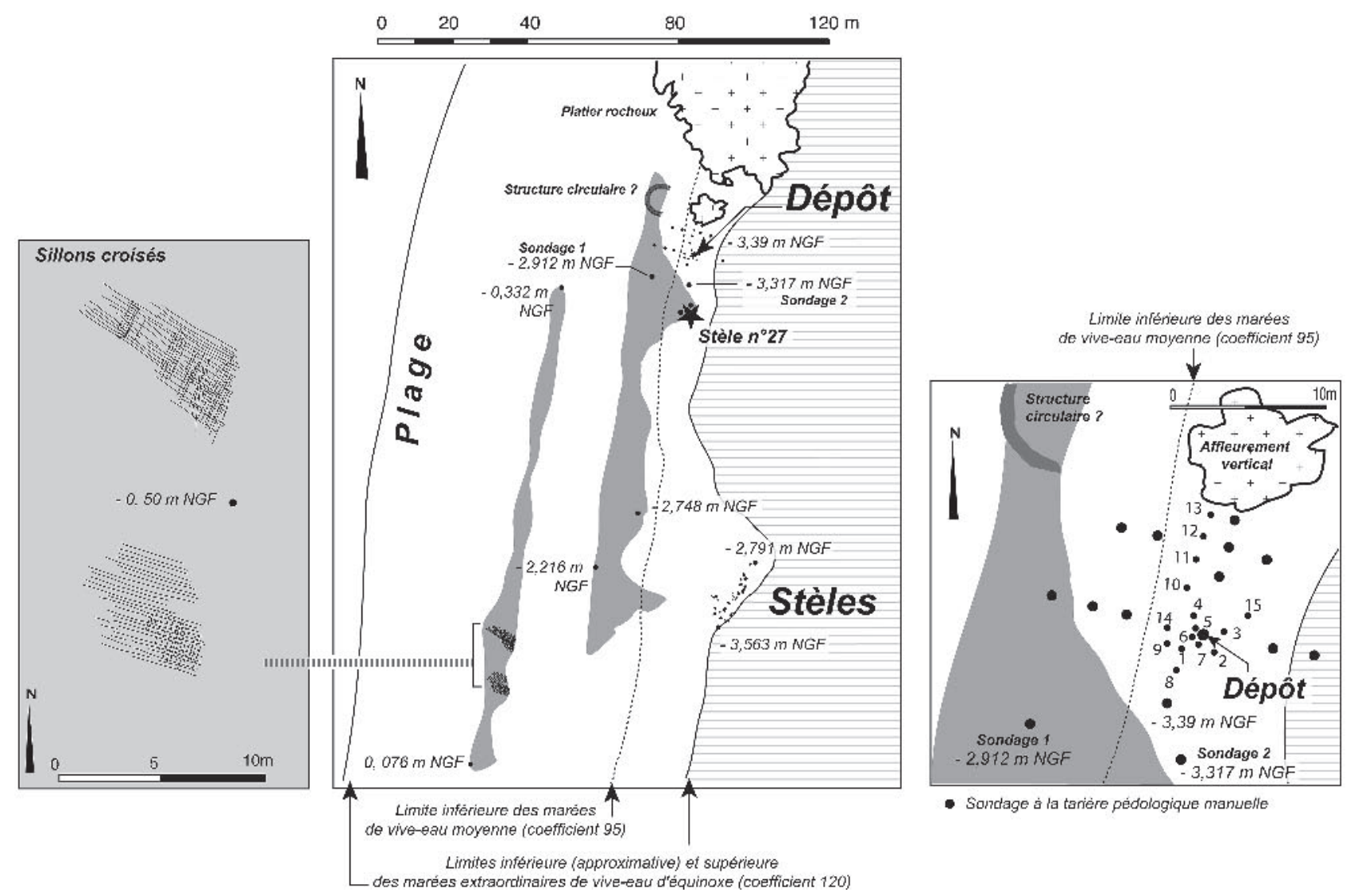

Fig. 4 - Localisation des tourbes sous-marines, du dépôt de haches et de l'ouvrage de stèles; emplacements des sondages menés à la tarière pédologique (DAO S. Cassen).

Fig. 4 - Location of the underwater peats, the axehead deposit and the stelae construction; sites of the surveys carried out with the pedological drill (CAD S. Cassen)

- d'identifier à terme la nature du site (dépôt en milieu tourbeux? contexte funéraire? structure type alignement de stèles?);

- de délimiter l'extension du site et son altimétrie (levés au GPS différentiel);

- d'observer et prélever le contexte sédimentaire.

\section{Les observations terrestres}

Il fut impossible de repérer des traces d'une structure ou même de l'encaissant qui aurait dû être visible à cet endroit et dont quelques résidus étaient encore collés aux haches.

Les rochers jugés suspects lors d'une précédente reconnaissance, à l'aplomb du lieu de la découverte, se sont révélés naturels, blocs verticalisés dans le substrat granitique, puis déchaussés par l'océan pour certains d'entre eux et écroulés, placés en porte-à-faux en rendant l'apparence trompeuse d'une construction. Compte tenu des traces d'érosion décelables aux sommets du massif (vasques, surfaces arrondies), il s'agit en revanche - fait essentiel - d'un probable affleurement granitique apparaissant déjà au temps du dépôt des lames de haches (fig. 3).

Cela dit, la spectaculaire découverte d'une file de blocs en granite à quelques dizaines de mètres du lieu de dépôt des haches relance l'intérêt du site, puisque ce type architectural est un des termes de l'alternative annoncée, conformément à un modèle interprétatif plus général (Boujot et al., 1995 ; Cassen et Vaquero Lastres, 2003b). Invisibles au regard non préparé, ces dalles allongées (une seule, massive, est probablement en place, plantée dans le sol de graviers) baignent en quasi-permanence dans l'eau malgré les plus forts coefficients de marées. Ces contraintes nous ont tout juste laissé le temps de faire un levé photographique vertical de chaque individu, ainsi qu'un levé géoréférencé des points saillants de chaque bloc formant une file apparente de $18 \mathrm{~m}$ de long pour 26 blocs inventoriés dans un premier temps; nous sommes en limite des plus basses eaux. À l'évidence, il ne s'agit pas d'une ancienne pêcherie, comme il est donné d'en voir plus au sud dans le secteur quiberonnais, mais bien d'un ouvrage de stèles.

Par ailleurs, une tourbe apparaît en différents endroits sous le sable et sur plusieurs centaines de $\mathrm{m}^{2}$, marquée de sillons de labours, dont une partie en labours croisés, à ne pas confondre avec les sillons d'écoulement de l'eau creusés dans le sédiment ferme sous le sable, perpendiculaires au rivage; des empreintes d'Ongulés divers (des Bovins ainsi que des Suidés) sont encore reconnaissables. Ce niveau est en correspondance avec la stratigraphie observée en arrière 
de l'actuel cordon dunaire, une zone marécageuse dans laquelle L. Gaudin a pu analyser une colonne pollinique couvrant la période considérée (Gaudin, 2004). Un sondage $\left(\mathrm{n}^{\circ} 1\right)$ à la tarière pédologique manuelle a révélé une puissance de $1,15 \mathrm{~m}$ de dépôts, s'organisant ainsi, de bas en haut : 15 à $20 \mathrm{~cm}$ de sable graveleux gris; puis $92 \mathrm{~cm}$ d'argile devenant de plus en plus sableuse avec l'augmentation de la profondeur, cette argile contenant des macrorestes végétaux; enfin $8 \mathrm{~cm}$ de tourbe très évoluée. Dans le sondage $n^{\circ} 2$ (fig. 4), à $20 \mathrm{~m}$ au sud des haches, $70 \mathrm{~cm}$ de dépôts ont été traversés avec, de bas en haut : $10 \mathrm{~cm}$ de graviers et $60 \mathrm{~cm}$ de sable argileux gris, la tourbe ici ayant été arrachée par l'océan ou jamais présente à cet endroit.

Enfin, un épandage de graviers, galets et moellons parsème par endroits la surface de l'estran quand elle est déblayée du sable marin et de la tourbe, notamment en vis-à-vis de l'affleurement remarquable à l'aplomb du dépôt des haches; ces groupements signent parfois la remontée du substrat à travers les altérites susjacentes. C'est dans ce contexte sédimentaire particulier qu'une dalle granitique est apparue ( $2 \mathrm{~m}$ de long, sans reconnaissance des limites), à quelques mètres au sud du dépôt, sans que l'on sache exactement - en l'absence d'une fouille qu'il n'était pas alors prioritaire d'entreprendre - si l'on est en présence tout simplement du rocher apparent, ou d'une stèle, ce que ne contredit pas un bloc en roche schisteuse distincte (mais non étrangère au milieu métamorphique local) plaqué profondément à une extrémité, émergeant comme une sorte de calage.

\section{Les observations sous-marines}

Pour un observateur placé sur la file de stèles, plusieurs blocs enfouis ( $\mathrm{n}^{\text {os }} 25$ et 26) ainsi que des taches sombres en mer en direction de l'est pouvaient suggérer un prolongement de la structure bien au-delà des plus basses mers. À partir de ces indications, les plongeurs dirigés par Elisabeth Veyrat (DRASSM) sont intervenus à marée haute afin de prospecter l'ensemble du secteur, c'est-à-dire le lieu du dépôt et la série de «menhirs».

Les conditions météorologiques clémentes ont permis de prospecter pendant près de cent minutes, par deux à six mètres de profondeur, dans deux secteurs immergés du Porh Fetan. En dépit de l'absence de houle, la visibilité sous-marine est restée médiocre et n'a guère dépassé le mètre. Au cours de la précédente basse mer, deux petites bouées lestées sur le site furent installées (fig. 5).
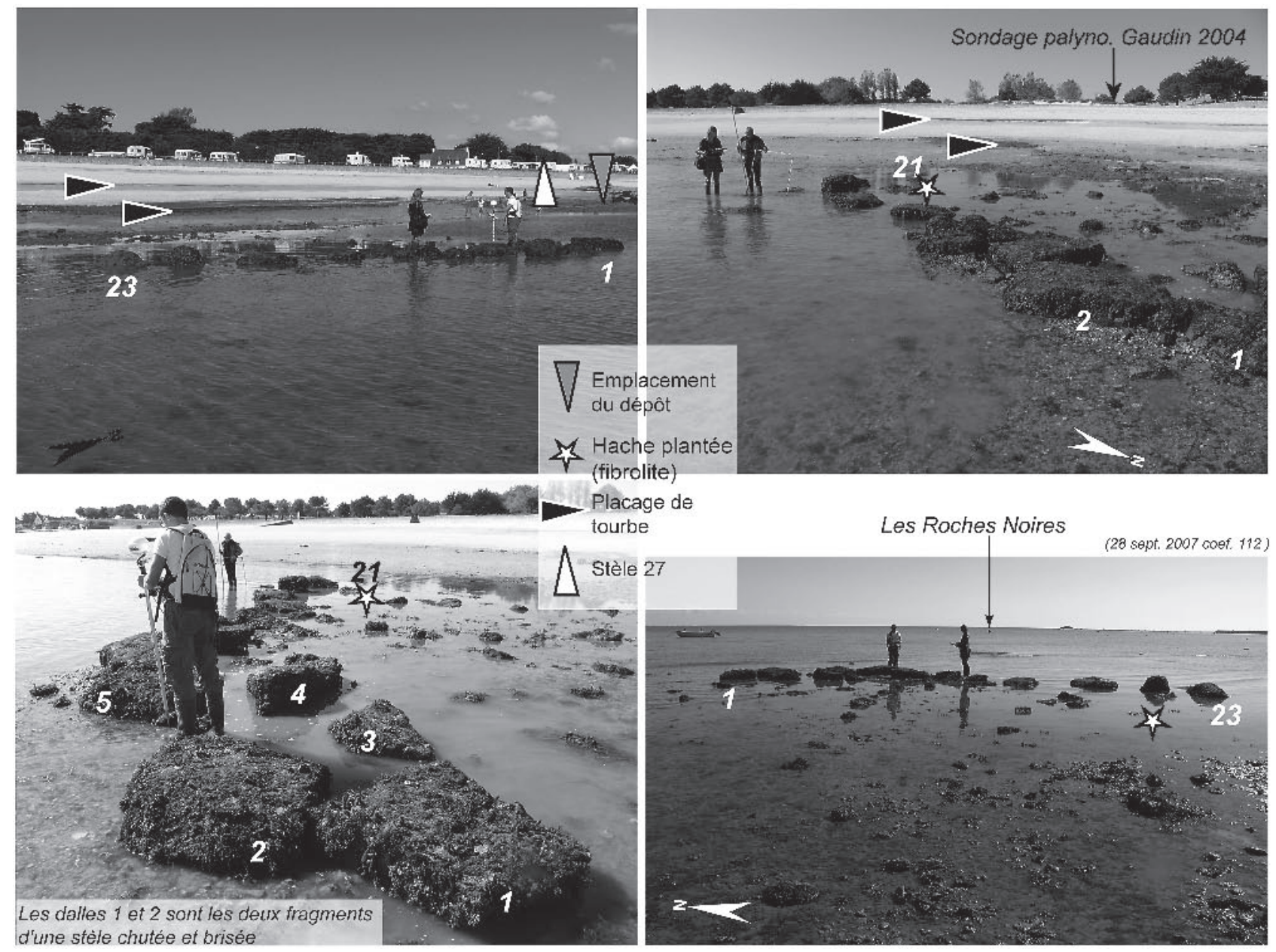
fibrolite)

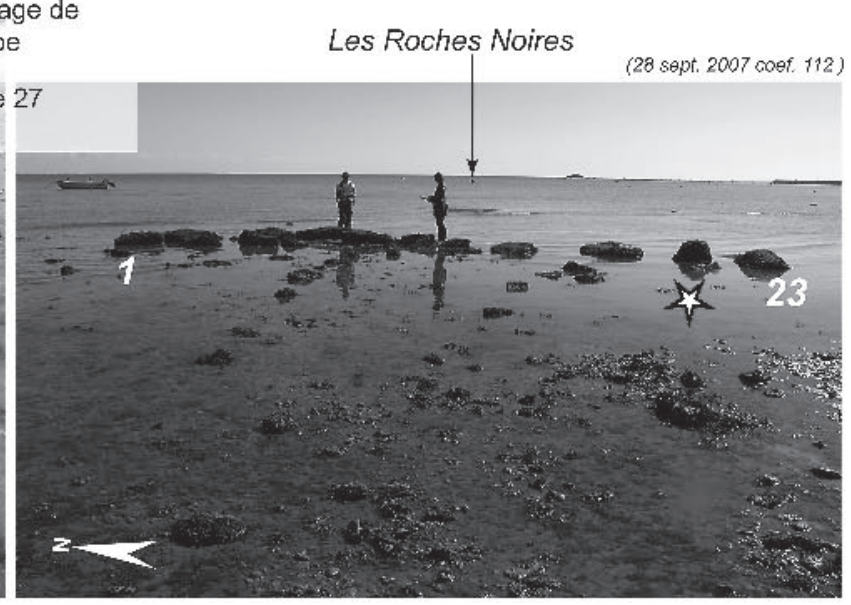

Fig. 5 - Différents points de vue sur l'ouvrage de stèles lors d'un fort coefficient de marée (clichés S. Cassen).

Fig. 5 - Various viewpoints of the stone alignment at the time of a spring tide (photos S. Cassen). 


\section{Secteur présumé de la découverte des haches}

Plusieurs prospections semi-circulaires de la zone ont été conduites à $5 \mathrm{~m}, 10 \mathrm{~m}, 15 \mathrm{~m}$ et $20 \mathrm{~m}$ de distance du point de découverte présumé des quatre haches en jadéite. Aucun détail notable n'a pu être relevé, mais l'absence de bancs de tourbe fossile vers le large est confirmée.

\section{Secteur de l'alignement des stèles}

Il fut décidé d'implanter, en début de plongée, trois fers à béton en frange orientale de l'alignement, afin de fournir une référence topographique locale permanente et de démarrer la prospection à partir de ces points. Hauts de $1,50 \mathrm{~m}$ pour un diamètre de $1 \mathrm{~cm}$, les fers à béton ont été profondément enfoncés dans le sol, à une distance respective de $6,50 \mathrm{~m}$ et 7,20 $\mathrm{m}$ les uns des autres. Les blocs près desquels les fers ont été placés sont respectivement les stèles $n^{\text {os }} 2,8$ et 26 (entre 5,3 et 5,6 $\mathrm{m}$ de profondeur).

Trois prospections circulaires ont été réalisées, vers le nord et vers le large, à l'est, à 10 m, 20 m et 40 m au-delà de l'alignement identifié en prospection terrestre. Plusieurs blocs sont regroupés autour de l'extrémité nord de l'alignement et de trois blocs de taille réduite alignés selon un cap compas de $50^{\circ}$ à partir du point $n^{\circ} 3$. Vers le large, trois blocs de faibles dimensions ont été découverts (section inférieure à $50 \mathrm{~cm}$ ) plus ou moins alignés selon un cap compas de $50^{\circ}$ à partir du fer à béton $n^{\circ} 3$. Vers le nord, dix pierres de dimensions variables, de part et d'autre des blocs désignés $\mathrm{n}^{\text {os }} 0$ et 1 lors de la prospection terrestre, complètent l'alignement repéré à basse mer et le prolongent sensiblement à son extrémité nord, brisant l'isolement apparent du bloc $\mathrm{n}^{\circ} 0$.

Le plan des dalles découvertes a été levé à partir d'un simple croquis non coté des blocs et de l'utilisation de décamètres tendus à partir des trois fers à béton, sans tenir compte des distorsions éventuelles causées par les blocs. Les données recueillies au cours de cette première prospection sous-marine devront être complétées par le positionnement GPS des trois fers à béton et une nouvelle opération sous-marine visant à topographier en surface, par mer calme, au moyen de bouées étarquées indiquant en surface le point de chacun des blocs.

À l'occasion des grandes marées du mois d'octobre (coef. 106/108 et 109/109), une nouvelle mission partagée de surveillance et d'observation est programmée sur deux journées. Dans un premier temps, l'emplacement exact du dépôt des haches semblait avoir été trouvé sous forme d'une fosse grossièrement circulaire, remplie d'une vase fine argileuse bleu-vert dans un encaissant de gravier; mais plusieurs sondages à la tarière ont permis de nous faire une meilleure idée du contexte sédimentaire (compliqué par un afflux permanent d'eau), qui ne confirme pas cette pseudo-fosse; ce complexe d'estran peut présenter un aspect similaire en d'autres endroits, selon la topographie cachée des lieux. En effet, une couche argileuse, puis argilo-sableuse gris sombre, passant ensuite au bleu-vert (sur au moins $60 \mathrm{~cm}$ de puissance) - celle qui est censée combler la fosse -, est identifiable sous la vraie tourbe de l'estran et se poursuit jusqu'à l'emplacement présumé du dépôt, déposée sur les couches de graviers et altérites plus ou moins oxydés (couleur rouille).

Nous sommes en réalité placés dans la position difficile de l'observateur en surface d'une stratigraphie couchée sur une ancienne zone humide, en arrière d'un cordon dunaire en place dès le $\mathrm{VI}^{\mathrm{e}}$ millénaire, aux prises avec un relief «interne» occulté par le colmatage, délicat à restituer avec peu de moyens et en si peu de temps. Dans l'urgence, nous avons cependant sondé (le 27/10) à l'aide d'une tarière pédologique manuelle autour du point de dépôt, puis en direction de l'affleurement rocheux; la liste indicative des sédimentations est la suivante, pour une colonne moyenne de 50-60 cm, chaque sondage étant numéroté de 1 à 15 :

1 - sédiment vaseux gris-bleu (correspondant au prélèvement fait le 26/10); en profondeur, sable brun clair;

2 - graviers oxydés grossiers en surface; en profondeur, sable roux oxydé;

3 - sable grossier orangé avec interstrates de lits de tourbe;

4 - tourbe sableuse (semblable à celle de l'échantillon prélevé par le découvreur) passant en profondeur au sable brun clair;

5 - graviers grossiers grisâtres (déblais fosse du 26/10/2007?); en profondeur, sable;

6 - sédiment argileux fin grisâtre avec sable; en profondeur, sable brun clair;

7 - graviers; en profondeur, sable brun clair;

8 - sédiment argileux gris-bleu; en profondeur avec de plus en plus de sable;

9 - argile marron avec passes tourbeuses (très plastiques); prélèvement; en profondeur, sable et gros graviers;

10 - sable noirâtre allant vers le gris en profondeur; présence de quelques galets en quartz blanc;

11 - sable gris avec trace d'oxydation; en profondeur, sable oxydé;

12 - sable gris avec présence de graviers; en profondeur, sable, graviers, galets ;

13 - graviers gris à noirâtre; en profondeur, sable grossier;

14 - sable argileux gris;

15 - sable tourbeux.

Fig. 6 (à droite) - Plan des stèles couchées, enfouies ou encore debout $\left(n^{\circ} 22\right)$; localisation de la lame polie en sillimanite plantée au pied de la stèle 21 ; les altitudes prises au GPS différentiel devront être confirmées, le dénivelé entre les extrémités paraissant trop important par rapport à l'expérience du terrain (clichés S. Cassen; DAO S. Cassen, S. Poirier).

Fig. 6 (right) - Plan of the stelae: lying, buried or upright $\left(n^{\circ} 22\right)$, location of the polished sillimanite blade at the base of stele 21 (photos S. Cassen; CAD S. Cassen, S. Poirier). 

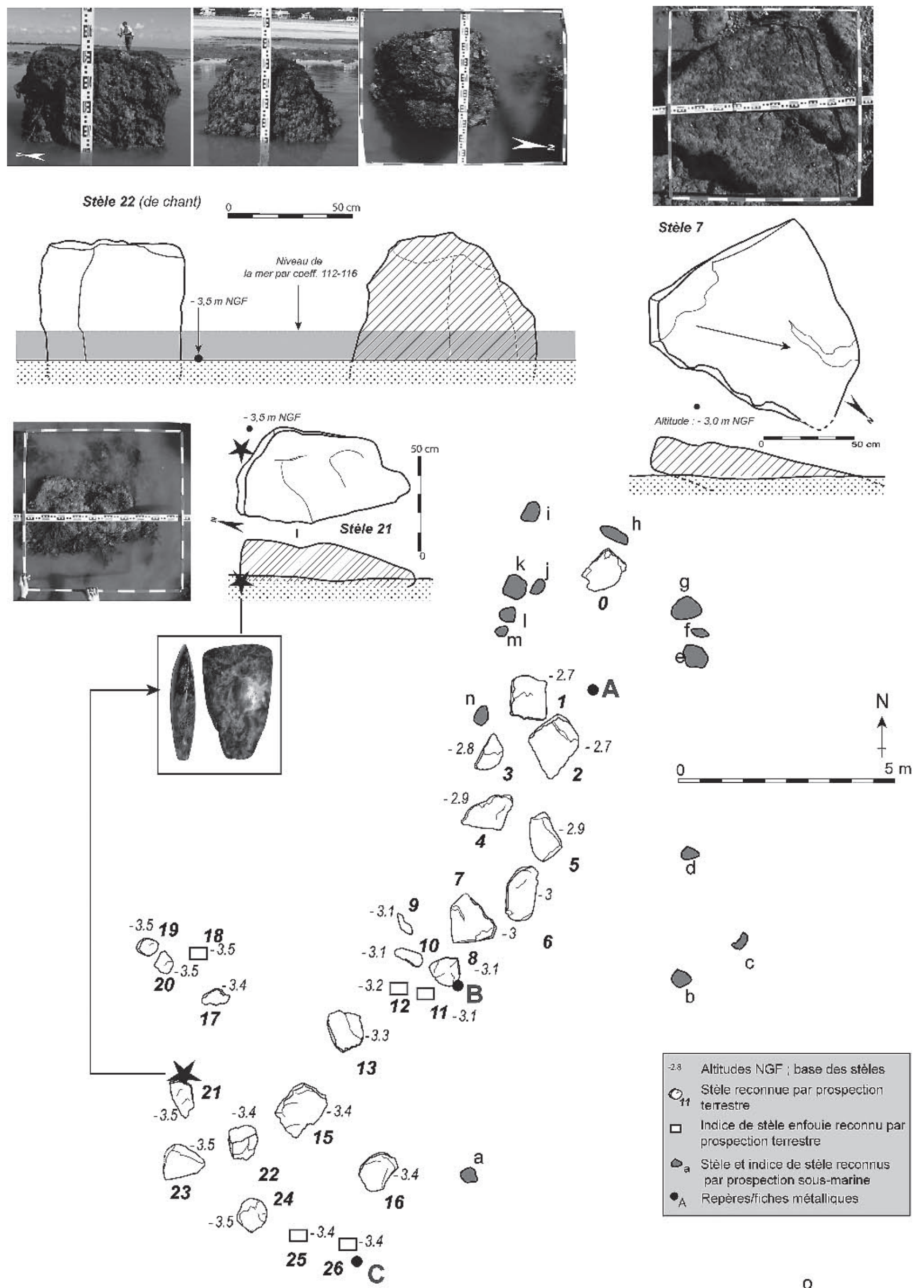
-2.8 Altitudes NGF ; base des stèles
O. Stele reconnue par prospection
11 teitestre
ㅁ Indice de stèle enfouie reconnu par prospection terrestre
- Stèle et indice de stèle reconnus par prospection sous-marine
- A Repèresifiches métalliques

$$
\square^{-3.4} \square^{-3.4} \mathrm{C}
$$


Sous la tourbe, présence de sédiment fin très argileux, gris sombre, allant vers le verdâtre, jaunâtre (hydromorphe) en profondeur $(66 \mathrm{~cm}$ atteints, sans toucher le plancher).

En tout cas, le sédiment adhérant aux haches, de couleur très sombre, était parfaitement conforme au niveau argileux collant identifié sous la mince couche de tourbe qui part par plaques au fil des marées, une couche parfois très indurée, compacte, englobant des graviers centimétriques à sa base, une «croûte» ainsi décrite par les découvreurs qui en avaient prélevé un échantillon; cette couche indurée et perforée par les mollusques marins résiste par endroits, en particulier au contact des amas de graviers, galets et pierres plus anguleuses qui signent par endroits une remontée du substrat ou un «sol» mal caractérisé. C'est la couche de tourbe qui a préservé intacts les tranchants des haches et les a en même temps libérés quand l'océan arracha ce manteau protecteur.

Lors des dernières fortes marées à 99/100 de coefficient pour l'année 2007, la configuration des lieux a cette fois notablement changé, puisque le sable recouvre entièrement le secteur sous surveillance, sur une puissance de $30 \mathrm{~cm}$ à la hauteur du dépôt pour atteindre un mètre d'épaisseur dix mètres en contrebas. En revanche, la tourbe apparente située quelques mètres au-dessus (vers le haut de la plage) est plus largement découverte et fera l'objet d'un nouveau prélèvement d'une branche d'arbre. Ce niveau intéressant permet alors d'entrevoir la forme apparente d'une structure semi-circulaire mesurant entre $8 \mathrm{~m}$ (interne) et $10 \mathrm{~m}$ de diamètre (externe) composée d'une dépression («fossé») de faible profondeur $(20-30 \mathrm{~cm})$, mais clairement marquée sur plus d'un mètre de large. Le cercle n'est pas refermé vers le bas. La nature de cette forme, située une dizaine de mètres au-dessus et au nord-ouest du dépôt, à la latitude de l'affleurement rocheux vertical, ne peut être assurée à l'heure actuelle : structure anthropique ou jeu des écoulements d'eau dans le substrat meuble (chenal de marée)?... Une dalle $(40 \mathrm{~cm})$ en roche schisteuse étrangère au sous-sol granitique local est dégagée du sable à $2 \mathrm{~m}$ au NO de cette anomalie.

De nouveaux sondages à la tarière permettent de rechercher le substrat de part et d'autre du lieu de dépôt, confirmant une entaille assez profonde (rocher non atteint, au-delà de la tige de $1 \mathrm{~m}$ du sondeur) au pied de l'ancien affleurement situé au nord; cette dépression est étroite (3-5 m de large ?), comblée de sédiments fins à grossiers selon la profondeur et surmontée du niveau de tourbe sur une faible épaisseur. Tout juste au sud du dépôt, des graviers et altérites ont accroché la tourbe, lui permettant par endroits de résister aux vagues et aux courants de jusant. Encore plus au sud, la tourbe est scellée par des niveaux grossiers (graviers et sables). Ce niveau correspond à un niveau d'altérite (cuirasse ferrugineuse) permettant la préservation par endroits de la tourbe de l'action érosive des vagues et des courants tidaux.

Sous réserve d'études spécialisées qu'il conviendrait de mettre en œuvre, l'implantation des lames de haches a été faite dans un contexte sédimentaire argilo-sableux d'origine fluviomarine, zone humide étendue mais contrainte à cet endroit par des émergences du substrat, en particulier par l'affleurement remarquable des dalles verticalisées au pied desquelles les haches ont été plantées; non pas en profondeur, mais seulement enfouies en surface si l'on admet que les tranchants qui ont été protégés par la couche de tourbe $(10-15 \mathrm{~cm})$ se situaient à la transition entre ces deux entités lithologiques, les vases d'une part (le «bri» ou encore la «tangue » selon les régions) avec des graviers roulés à la base de la séquence, la tourbe organique sus-jacente d'autre part.

Au contraire de la zone du dépôt ayant connu un nouvel ensablement depuis notre dernière visite d'octobre, le secteur des stèles a bénéficié d'un amaigrissement des sables marins pour laisser entrevoir de larges placages de tourbe surmontant des vases argilosableuses grises; ce sol tourbeux vient s'interrompre à quelques mètres des graviers et altérites supportant les dalles couchées, indices que nous avons dans un premier temps rapprochés d'une éventuelle remontée du substrat granitique (cf. rapport d'opération), mais que des sondages à la tarière pédologique ont infirmés, révélant par dessous un sédiment fin argileux noirâtre. Bien que les stèles baignent ce jour-là dans l'eau, laissant à peine deviner leurs faces supérieures, excepté pour la stèle de chant $\mathrm{n}^{\circ} 22$, une rapide inspection dans ce milieu calme et rendu fort transparent par l'effet d'un vent de terre permet de découvrir une petite lame de hache polie dégagée des graviers au nord de la base du monolithe $\mathrm{n}^{\circ} 21$ (fig. 6). Plantée de biais et sur tranche dans le gravier, elle semble avoir été raclée au tranchant par un outil de pêcheur à pied; la roche est une fibrolite (sillimanite); le poli des surfaces est remarquable, qui plaide là encore pour un enfouissement protecteur face à l'agression marine. Sous $20 \mathrm{~cm}$ d'eau, il fut impossible de mieux sonder autour du point de découverte, la récolte étant déjà en soi le résultat d'un heureux hasard...

En avril, par un coefficient de 109, le plus fort calculé pour toute l'année 2008 , le ré-ensablement généralisé de la plage est constaté, exception faite de la surface à la hauteur de l'ouvrage ruiné de stèles où la tourbe est encore dégagée et fera l'objet d'un prélèvement. Dans un contexte peu favorable malgré le coefficient annoncé, la mer baignant l'ensemble de la structure, deux sondages à la tarière pédologique permettent de vérifier que le rocher n'est pas le support sous-jacent aux graviers grossiers épandus autour de certaines stèles et qu'un sédiment argilo-sableux gris se développe sur au moins $50 \mathrm{~cm}$ de puissance. Les stèles ont donc été implantées dans un terrain bas colmaté, à l'image d'autres architectures de ce type connues régionalement dans de semblables environnements.

Fig. 7 (à droite) - Les lames de haches et leur disposition reconstituée dans le sol d'après les indications mesurées de A. MacHale (clichés H. Neveu-Derotrie; DAO S. Cassen).

Fig. 7 (right) - Axeheads and their position resituated in the ground according to the measured indications of A. MacHale (photos H. NeveuDerotrie; CAD S. Cassen). 


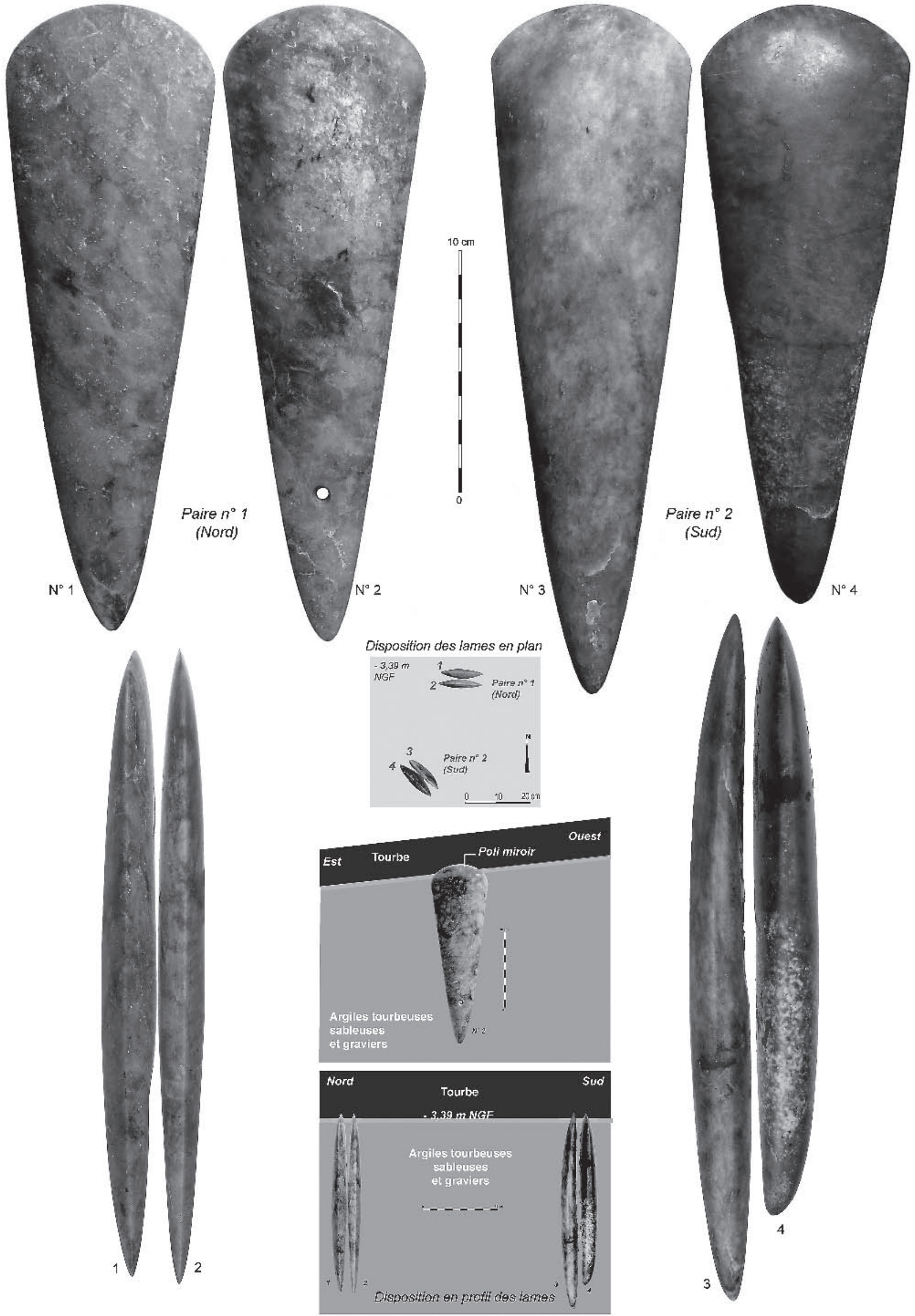


Le monolithe entrevu le 28 septembre 2007 auprès du dépôt des haches est également sondé sur son bord septentrional; ici encore, sous les graviers, un sédiment argilo-tourbeux sombre sur au moins $50 \mathrm{~cm}$ de puissance plaide pour une implantation dans un contexte sédimentaire humide; il ne s'agit donc pas d'un affleurement granitique et le calage d'origine est bel et bien préservé en son extrémité occidentale.

\section{PREMIÈRES OBSERVATIONS, PREMIËRES ANALYSES SUR LES LAMES POLIES}

\section{Descriptif des lames}

\section{La paire nord, ou paire $n^{\circ} 1$}

La première lame polie $\left(\mathrm{n}^{\circ} 1\right)$ appartient au type Tumiac non perforé (fig. 7 et 8 ). Il s'agit d'une jadéitite vert pâle veinée de blanc. Elle est parfaitement polie, à l'exception de la face inférieure qui présente une large fossette au niveau du talon ainsi que deux autres anfractuosités. La section est lenticulaire. Un des bords est rectiligne, l'autre est légèrement convexe. Cette dissymétrie se retrouve à la jonction entre le tranchant et un bord; sur un côté, le tranchant s'élargit.

Longueur $=23,8 \mathrm{~cm}$

Largeur $=7,9 \mathrm{~cm}$

Épaisseur $=2,1 \mathrm{~cm}$

Poids $=518 \mathrm{~g}$

La seconde lame polie $\left(\mathrm{n}^{\circ} 2\right)$ appartient au type Tumiac perforé (fig. 7 et 8 ). La jadéitite est similaire à la précédente. Très proche de sa jumelle, elle en diffère cependant par une plus grande finesse, une finition encore plus poussée et une plus grande symétrie. On remarquera également l'élargissement visible au niveau du tranchant. La perforation est bitronconique. Là aussi, la section est lenticulaire plate.

Longueur $=24,1 \mathrm{~cm}$

Largeur $=7,7 \mathrm{~cm}$

Épaisseur $=1,8 \mathrm{~cm}$

Poids $=398 \mathrm{~g}$

\section{La paire sud, ou paire $n^{\circ} 2$}

La troisième lame polie $\left(n^{\circ} 3\right)$ appartient au type Saint-Michel (fig. 7 et 8). Elle a été façonnée dans une jadéitite vert pâle veinée de blanc, identique à celle constituant la paire précédente. Il s'agit de la plus grande du lot. Sa forme générale rentre dans un triangle allongé, ses bords sont légèrement convexes et se terminent en tranchant faiblement évasé, ce qui est la caractéristique principale du type avec une section ovale aplatie. Le tranchant est en excellent état; il a fait l'objet d'un réaffûtage visible sur une face. Une petite ébréchure de quelques millimètres à l'extrémité du tranchant est postérieure à la découverte. La face inférieure, partiellement concave, présente des anfractuosités non oblitérées par le polissage. Les bords montrent des facettes de polissage.

Longueur $=26,5 \mathrm{~cm}$

Largeur $=7,8 \mathrm{~cm}$

Épaisseur $=2,4 \mathrm{~cm}$

Poids $=682 \mathrm{~g}$

La quatrième lame polie $\left(n^{\circ} 4\right)$ appartient au type Chelles (fig. 7 et 8). Le matériau est encore une fois une jadéitite, mais différente des trois autres spécimens. La roche présente d'ailleurs une sorte de patine jaunâtre en surface, à l'exception du bord du tranchant qui conserve une couleur plus verte. À l'image des autres individus, la forme de la hache s'intègre dans un triangle allongé. Il s'agit de la lame la plus massive du lot et elle se rapproche en cela des lames de haches utilitaires.

Elle semble avoir subi deux phases de mise en forme.

La lame est tout d'abord polie et son talon est piqueté. Le piquetage est poussé au point d'avoir transformé les bords rectilignes d'origine en les rendant légèrement concaves. Le piquetage a été moins soutenu dans les 3-4 cm les plus proches de l'extrémité du talon, se concentrant exclusivement sur les bords.

Dans une seconde phase, l'objet est entièrement repris par polissage, mais les stigmates de l'opération sont encore visibles en transparence sous l'aspect de points d'impact blanchâtres. Postérieurement à ce polissage, une petite zone d'un bord avoisinant le talon a été piquetée. Les bords dans la moitié la plus proche du tranchant sont facettés, mais non pas équarris. En allant vers le talon, ils tendent à s'arrondir complètement. La section est donc ovale aplatie.

Longueur $=23,1 \mathrm{~cm}$

Largeur $=8,15 \mathrm{~cm}$

Épaisseur $=2,5 \mathrm{~cm}$

Poids $=664 \mathrm{~g}$

L'outil originel a dû être une grande lame d'abattage fonctionnelle, le piquetage annulaire facilitant l'emmanchement; puis le surpolissage, très probablement réalisé en Morbihan, a modifié la forme, l'éclat des surfaces, le fil du tranchant, suivant un schéma de transformation physique et symbolique désormais assez bien connu pour décrire ces objets survalorisés aux commencements du Néolithique en Armorique-sud.

\section{Identification des roches (tabl. 2)}

Intuitivement identifiées comme jadéites, les quatre lames ont été analysées par spectroradiométrie ${ }^{6}$ dans le cadre de la première année d'activité du programme JADE, prolongeant en cela une expérience antérieure déjà couronnée de succès (Pétrequin et al., 2005a et b). Il s'agit bien ici de jadéitites, et notamment d'un seul et même bloc originel provenant du versant italien des Alpes pour trois des quatre lames.

Dans les quatre cas, la jadéitite a été tirée des exploitations d'Oncino, vallon de Porco inférieur (Piémont), entre 1800 et $2200 \mathrm{~m}$ d'altitude (Pétrequin et al., 2006c). 


\section{Les dépôts en surface des lames}

Malgré un nettoyage plutôt appuyé des découvreurs (au couteau) afin d'éliminer l'argile collant aux objets, une fine croûte de couleur brun-sombre subsiste par endroits sur toutes les surfaces des quatre lames polies (fig. 9). Cette matière est encore plus visible sur les clichés des objets tout juste extraits de la vase.
Sous la loupe binoculaire, la pellicule paraît nettement minéralisée; elle ne renvoie pas l'image de débris végétaux malgré des nervures apparentes, non arborescentes. En l'absence d'analyses spécialisées et dans l'attente d'observations plus poussées, nous ne pouvons raisonnablement conclure sur la nature de cette enveloppe, même si l'étui en cuir peut réunir les qualités du contenant à la fois souple pour s'adapter aux formes

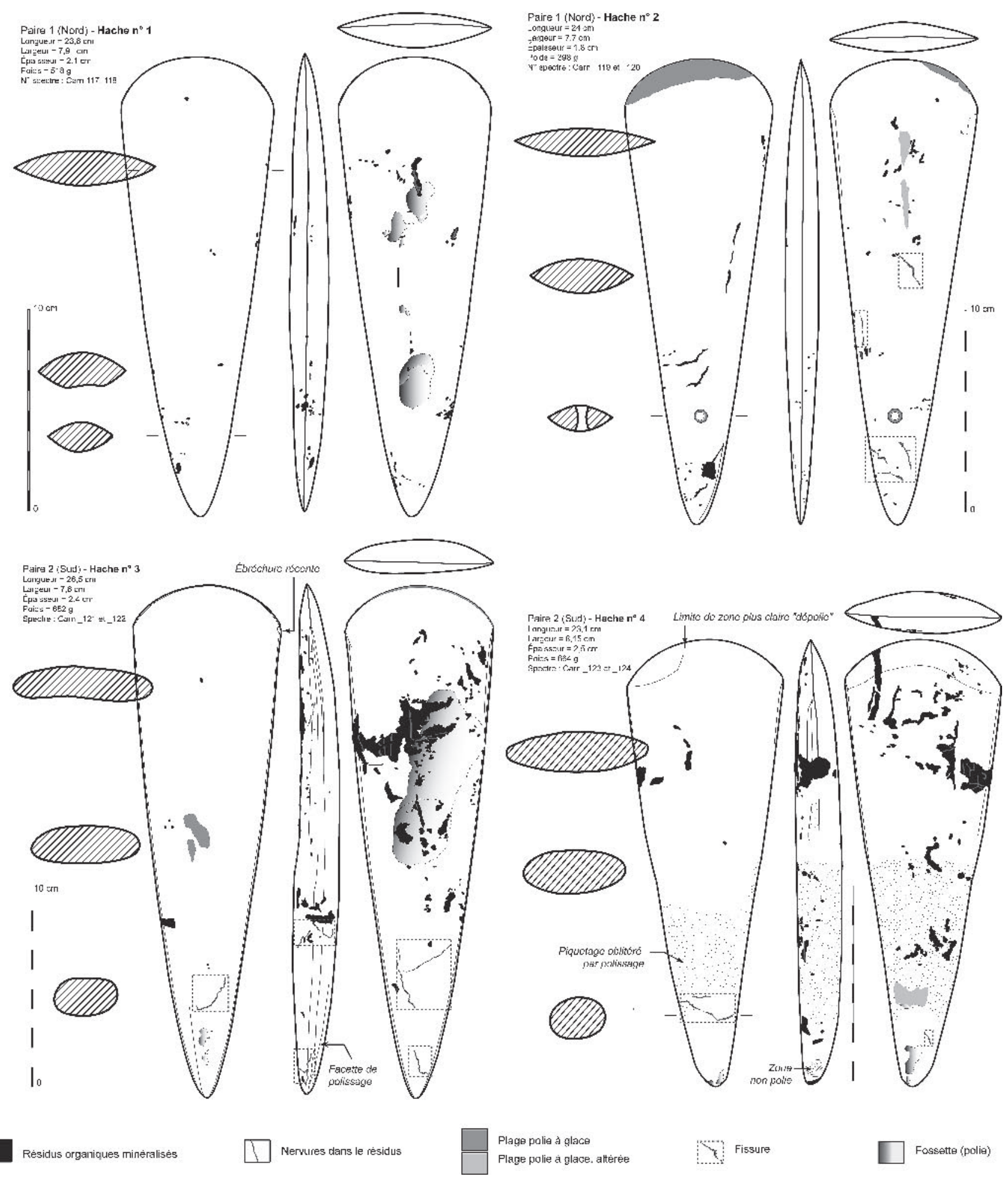

Fig. 8 - Analyse graphique des formes et surfaces des lames de haches (crayonnés S. Cassen, Y. Pailler; DAO S. Cassen, Y. Sparfel). Fig. 8 - Graphic analysis of the shapes and surfaces of the axeheads (drawings S. Cassen, Y. Pailler; CAD S. Cassen, Y. Sparfel). 


\begin{tabular}{|c|c|c|c|c|c|c|c|c|c|c|}
\hline CONTEXTE & TYPE & COUPE & Pol. & PIQU. & Perf. & $\begin{array}{l}\text { Long. } \\
\mathrm{cm}\end{array}$ & Larg. & Épais. & $N^{\circ}$ SPECTRE & $\begin{array}{l}\text { COULEUR, STRUCTURE } \\
\text { et ORIGINE de la roche }\end{array}$ \\
\hline $\begin{array}{l}\text { Paire nord, } \\
\text { hache } 1\end{array}$ & $\begin{array}{l}\text { Tumiac } \\
\text { non perforé }\end{array}$ & II E & 4 & $\begin{array}{l}\text { stigmates } \\
\text { de taille }\end{array}$ & & 23,8 & 7,9 & 2,1 & $\begin{array}{l}\text { Carn_117 et } \\
\text { et_118 }\end{array}$ & $\begin{array}{l}\text { jadéitite vert pâle, veinée vert } \\
\text { moyen, type Bulé - Oncino } \\
\text { (Cuneo, Piemonte, Italie), } \\
\text { vallon de Porco }\end{array}$ \\
\hline $\begin{array}{l}\text { Paire nord, } \\
\text { hache } 2\end{array}$ & $\begin{array}{l}\text { Tumiac } \\
\text { perforée }\end{array}$ & II F & 5 & & oui & 24,1 & 7,7 & 1,7 & $\begin{array}{l}\text { Carn_119 } \\
\text { et_120 }\end{array}$ & $\begin{array}{l}\text { jadéitite très fine, transparente, } \\
\text { même bloc que précédente - } \\
\text { Oncino, vallon de Porco }\end{array}$ \\
\hline $\begin{array}{l}\text { Paire sud, } \\
\text { hache } 3\end{array}$ & Saint-Michel & II B & 4 & & & 26,7 & 7,8 & 2,4 & $\begin{array}{l}\text { Carn_121 } \\
\text { et_122 }\end{array}$ & $\begin{array}{l}\text { jadéitite identique aux } 2 \text { haches } \\
\text { précédentes - Oncino, vallon } \\
\text { de Porco ou vallon de Bulè }\end{array}$ \\
\hline $\begin{array}{l}\text { Paire sud, } \\
\text { hache } 4\end{array}$ & Chelles & II B & 5 & $\begin{array}{l}\text { stigmates } \\
\text { de taille, } \\
\text { piquetage } \\
\text { annulaire }\end{array}$ & & 23,2 & 8,2 & 2,5 & $\begin{array}{l}\text { Carn_123 } \\
\text { et_124 }\end{array}$ & $\begin{array}{l}\text { jadéitite fine vert moyen à vert } \\
\text { bleuté, bloc différent des } \\
3 \text { précédentes - Oncino, vallon } \\
\text { de Porco }\end{array}$ \\
\hline
\end{tabular}

Tabl. 2 - Récapitulatif simplifié des observations typologiques et spectroradiométriques extraites de la base de données JADE (dir. P. Pétrequin). Tabl. 2 - Simplified summary of the typological and spectroradiometric observations extracted from the JADE data base (dir. P. Pétrequin).

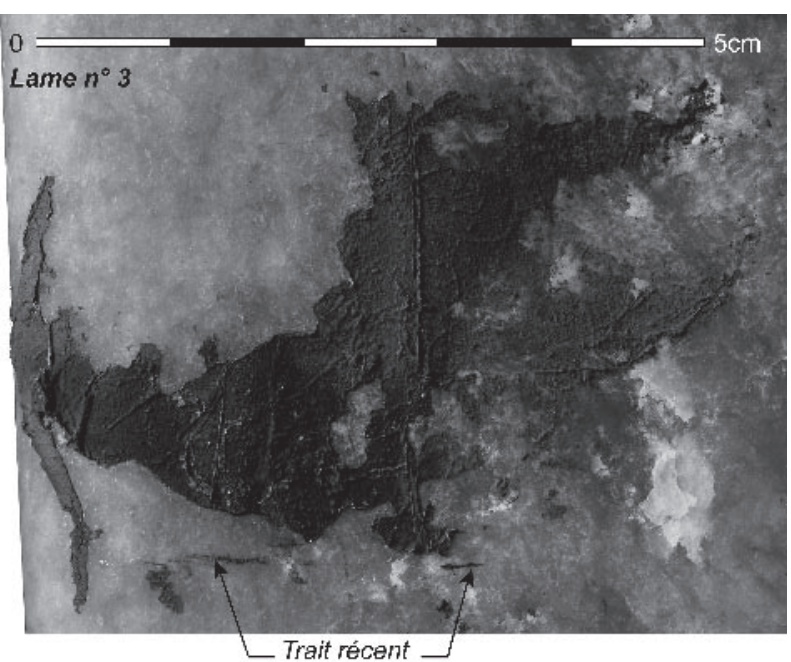

Fig. 9 - Vue rapprochée sur les résidus visibles sur une face de la lame $\mathrm{n}^{\circ} 3$ (cliché H. Neveu-Derotrie; DAO S. Cassen).

Fig. 9 - Close up view of the visible residues on a face of blade $n^{\circ} 3$ (photos H. Neveu-Derotrie; CAD S. Cassen).

et rigide pour maintenir les couples entre eux. On sait que sur des haches en silex découvertes dans les marais tourbeux de Hollande, des micropolis d'utilisation observés et reproduits expérimentalement ont été interprétés non pas comme un contacté répété avec des enveloppes souples assurant le transport des objets, mais comme le résultat de manipulations des haches, sorties de leur «écrin» de cuir ou de tissu et emballées à de fréquentes reprises (Wentink, 2008, p. 156).

\section{La typologie et la datation relative}

Grâce à un ordre typochronologique mis en place et testé à l'échelle européenne depuis plusieurs années (Pétrequin et al., 1997, 1998, 2002 et 2006a), toute analyse visuelle simple des plus grandes lames en roches alpines permet d'assurer une première ordination dans la nébuleuse apparente. Trois types ont été reconnus au Petit Rohu, dont deux historiquement établis par P. Pétrequin en référence à des ethnonymes morbihannais (tombes de Tumiac en Arzon et SaintMichel en Carnac) : il s'agit ici des types Tumiac (Tumiac perforé), Saint-Michel et Chelles, annoncés dans les paragraphes précédents.

Confrontés aux données de l'ordre chronoculturel renouvelé en Armorique, notamment par association des grandes lames surpolies en jadéitite : avec des bracelets en pierre dont le seul utilisateur, avec les bracelets en terre cuite, est actuellement le VSG/ASP en Bretagne (Cassen et al., 1998; Herbaut et Pailler, 2000; sur la fig. 13, mentionnons Mané er Hroëck, Saint-Julien, Plouay, Saint-Brévin), d'une part; avec les céramiques de la culture Castellic dont l'étape formative est antérieure au Chasséen au Nord de la France, d'autre part (Boujot et Cassen, 1992; Cassen, 1993 et 2000d; Cassen et Pétrequin, 1999), et confortés par deux analyses radiocarbone (sur charbons et ossement) concordantes effectuées dans le caveau du tumulus Saint-Michel, s'ajoutant à un résultat plus ancien identique obtenu sur cet ensemble clos (47004400 av. J.-C. ; Pétrequin et al., 2003 et 2005a ; Cassen, 2003 ; Schulting et al., à paraître), les types reconnus au Petit Rohu permettent une estimation fiable en termes de chronologie relative afin de situer ce dépôt dans la seconde moitié du $\mathrm{V}^{\mathrm{e}}$ millénaire av. J.-C.

\section{CONTEXTES}

\section{L'environnement maritime immédiat}

Première source informative en soi, les tourbes sousmarines visibles à Porh Fetan (fig. 10) (et en réalité présentes par intermittence tout au long du bord oriental de la presqu'île et sur le littoral nord de la baie ainsi qu'au sud dans les îles ; Marsille, 1930) sont un témoignage ancien de la confrontation existant entre, d'une part, une vallée orientée est-ouest dans un relief généralement faible mais plus accentué à l'ouest sur la côte sauvage et, d'autre part, l'océan dont les épisodes transgressifs contrarient depuis des millénaires le débouché hydrologique naturel vers l'est. Barrée par la 


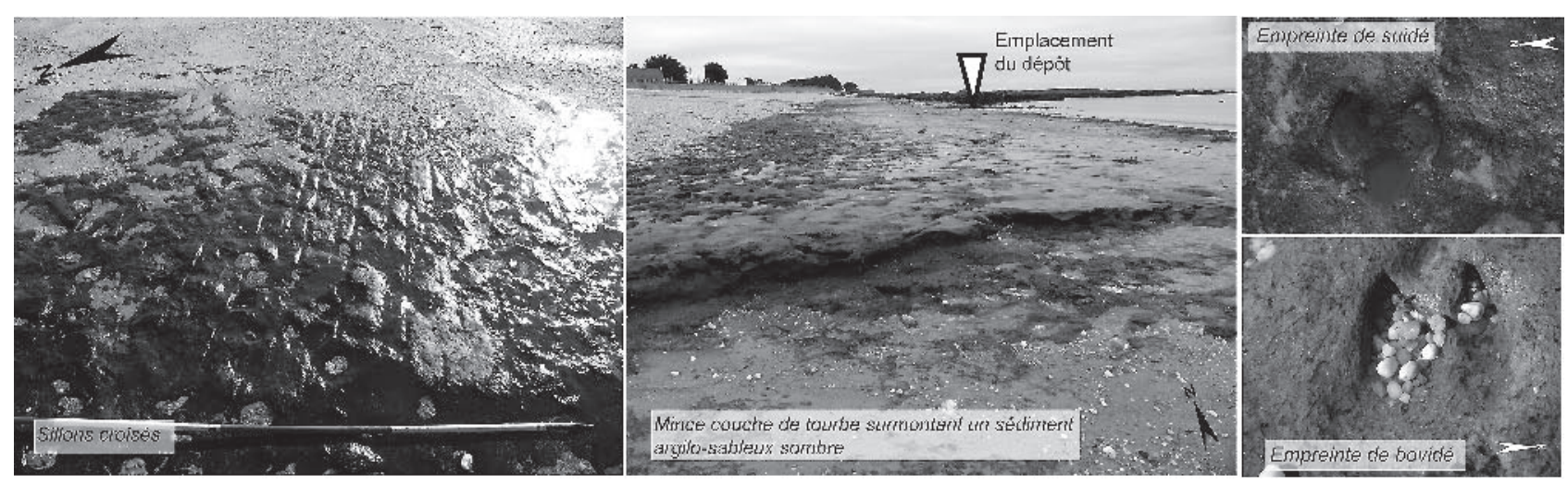

Fig. 10 - Marques de sillons croisés et empreintes d'animaux en surface des tourbes, sus-jacentes à un niveau argileux (clichés C. Boujot, S. Cassen, E. Vigier).

Fig. 10-Marks of cross furrows and of animal prints on the peat surface, overlying a clayey level (photos C. Boujot, S. Cassen, E. Vigier)

dune littorale, cette vallée où coule un ruisseau permanent (une présence assez rare dans la presqu'île) a donc préservé des accumulations sédimentaires (la tourbe sera exploitée comme combustible dans le marais de Parco jusqu'à la fin du XIX ${ }^{\mathrm{e}}$ siècle) (Lavenot, 1888) dont la formation est en partie reliée à la remontée du niveau marin, en particulier lorsque les tourbes qui recouvrent le dépôt et les stèles se forment en arrière de ce cordon dunaire, à une époque encore imprécise à l'échelle de la Préhistoire récente.

Sillons croisés des anciennes façons culturales et empreintes d'animaux en surface de ces tourbes rassemblent un second ensemble de témoignages, celui du passage des hommes quand les pratiques agricoles marquent les sols développés sur ces niveaux organiques, sans doute devenus moins humides à un certain moment de leur histoire, à l'image des tourbes sousmarines à sillons parallèles que l'on peut observer à Bretignolles-sur-Mer (Vendée). Mais on n'évacuera pas sans réflexion l'autre terme de l'alternative, celui relatif à la récolte des sablons en vue de leur lixiviation pour obtenir une saumure propre à être chauffée et permettre ainsi la cristallisation du sel marin (Cassen, 2000c ; Cassen et al., 2004) ; car cette récolte s'apparente à une forme de labour croisé puisque l'utilisation d'un instrument (un racloir large : le haveau, havet ou havel dans la terminologie normande), tiré par un animal, déterminait des «sillons» (les havelées) dans le sable en haut de grève, de préférence à l'embouchure des rivières ou au fond des anses et des baies (Pierre, 1852 , p. 16) ; le sable rejeté était ramené en tas à l'intersection de chaque havelée, plus ou moins perpendiculaires entre elles, rendant visuellement une sorte de damier. Nous ne savons pas exactement ce que peut donner expérimentalement sur le terrain une telle pratique, abandonnée progressivement au XIX ${ }^{\mathrm{e}}$; conservons-la néanmoins en mémoire. En ce cas, ce n'est pas un horizon humifère qui couvrait la tourbe mais bien des sables (comme aujourd'hui) et/ou des vases marines.

Enfin, troisième source d'informations, le sondage opéré dans le marais de Parco par L. Gaudin en arrière du cordon dunaire permet de conjoindre l'évolution naturelle du bassin en question, depuis le Tardiglacaire, et l'intervention progressive de l'homme dans cet écosystème spécifique (Gaudin, 2004). Un carottier a permis le prélèvement des sédiments jusqu'à une profondeur de $520 \mathrm{~cm}$ à l'est du marais (coordonnées Lambert II : X = 189 125, 464 m et $\mathrm{Y}=292$ 358, $011 \mathrm{~m})$. Le sommet du sondage correspond à une altitude calculée à partir d'une moyenne de dix valeurs prises par GPS, soit $\mathrm{z}=3,746 \mathrm{~m}$ (NGF).

La lithostratigraphie observée est la suivante :

- $0 \mathrm{~cm}-65 \mathrm{~cm}$ : tourbe fibreuse peu décomposée;

- $65 \mathrm{~cm}-105 \mathrm{~cm}$ : tourbe sablo-argileuse;

- $105 \mathrm{~cm}-130 \mathrm{~cm}$ : sableux avec quelques inclusions de macrorestes (racines);

- $130 \mathrm{~cm}-325 \mathrm{~cm}$ : tourbe argileuse;

- $325 \mathrm{~cm}-355 \mathrm{~cm}$ : argile tourbeuse;

- $355 \mathrm{~cm}-410 \mathrm{~cm}$ : tourbe argileuse;

- $410 \mathrm{~cm}-415 \mathrm{~cm}$ : argile tourbeuse;

- $415 \mathrm{~cm}-435 \mathrm{~cm}$ : tourbe argileuse;

- $435 \mathrm{~cm}-465 \mathrm{~cm}$ : argile organique (les quelques inclusions de macrorestes se raréfiant très rapidement avec la profondeur);

- $465 \mathrm{~cm}-485 \mathrm{~cm}$ : argile;

- $485 \mathrm{~cm}-510 \mathrm{~cm}$ : argile sableuse, avec quelques traces d'oxydation;

- $510 \mathrm{~cm}-520 \mathrm{~cm}$ : sable limoneux avec quelques cailloux.

Cinq échantillons ont fait l'objet d'une datation radiocarbone dont une en AMS (niveau 485-487); il n'a pas été possible d'obtenir des datations dans le fond du sondage à cause de la trop faible teneur en matières organiques, même en AMS (tabl. 3).

Sans entrer dans l'analyse détaillée des résultats obtenus et pour simplement rester dans le cadre de cet article de divulgation, on retiendra néanmoins les observations suivantes (fig. 11).

$\mathrm{Au} \mathrm{VI}{ }^{\mathrm{e}}$ millénaire av. J.-C. (le milieu de la zone g de L. Gaudin : $441 \mathrm{~cm}-416 \mathrm{~cm}$ ), le taux de pollens d'arbres se stabilise à $15 \%$ après avoir montré d'importantes variations dans les couches inférieures. L'augmentation brutale de la richesse taxonomique 


\begin{tabular}{|l|c|c|c|c|}
\hline Code Labo & $\begin{array}{c}\text { Coordonnées } \\
\text { stratigraphiques } \\
\text { des échantillons } \mathbf{( c m )}\end{array}$ & $\begin{array}{c}\text { Type de } \\
\text { sédiments }\end{array}$ & Âge (BP) & $\begin{array}{c}\text { Âge calibré } \\
\text { (à partir des données atmosphériques de Stuiver et al. } \\
\text { (1998); Oxcal v. 3.5, Bronk Ramsey (1995); } \\
\text { Avec une probabilité de 95,4 \% }\end{array}$ \\
\hline LY-11481 & $130-132,5$ & tourbe argileuse & $1190 \pm 50$ & $\begin{array}{c}690 \mathrm{AD}(9.2 \%) 750 \mathrm{AD} \\
760 \mathrm{AD}(86.2 \%) 980 \mathrm{AD}\end{array}$ \\
\hline Beta-185617 & $257,5-260$ & tourbe argileuse & $2810 \pm 40$ & $1070 \mathrm{BC}(95.4 \%) 830 \mathrm{BC}$ \\
\hline LY-11482 & $320-322,5$ & tourbe argileuse & $3570 \pm 35$ & $\begin{array}{c}2030 \mathrm{BC}(77.6 \%) 1860 \mathrm{BC} \\
1850 \mathrm{BC}(17.8 \%) 1770 \mathrm{BC}\end{array}$ \\
\hline UL-2659 & $427,5-430$ & tourbe argileuse & $6420 \pm 120$ & $5650 \mathrm{BC}(95.4 \%) 5050 \mathrm{BC}$ \\
\hline
\end{tabular}

Tabl. 3 - Récapitulatif des datations ${ }^{14} \mathrm{C}$ effectuées dans le sondage du Pargo (d'après Gaudin, 2004).

Tabl. 3 - Summary of the 14C dating carried out in the Pargo survey (after Gaudin 2004)

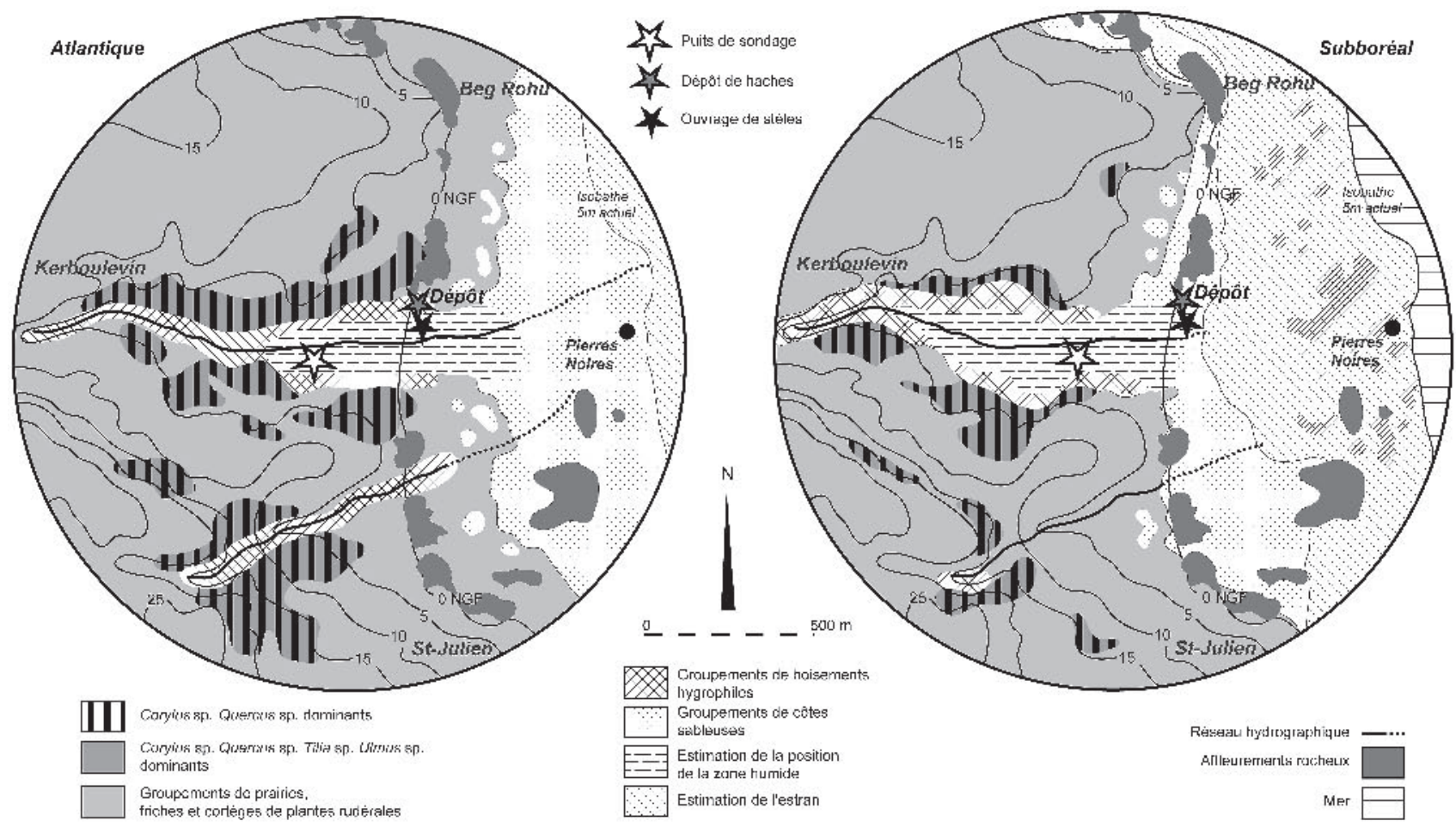

Fig. 11 - Sondage pollinique Pargo. Proposition de changement dans la mosaïque paysagère autour de la tourbière de Pargo/Rohu/Porh Fetan, du milieu du Ve millénaire av. J.-C. (Atlantique - phase écologique PAR 3 : zones g et h du sondage) au Subboréal (phase écologique PAR 4 : zones i et j); estimation du trait de côte; les isoclines actuelles sont issues de la carte de l'IGN au 1/25000 (d'après Gaudin, 2004; DAO S. Cassen).

Fig. 11 - Pollen survey in Pargo. Proposal for a change in the landscape mosaic around the peat bog of Pargo/Rohu/Porh Fetan, from the middle of the 5th millennium cal. BC (Atlantic - ecological phase PAR 3: zones g and hof the survey) to the Subboreal (ecological phase PAR 4: zones $i$ and j); an estimate of the coast line; the current isoclinal lines are taken from the IGN map, scale 1:25000 (after Gaudin, 2004; CAD S. Cassen).

dénote une rupture nette au regard des cortèges retrouvés dans les niveaux antérieurs. Dans la zone humide concernée, le paysage est marqué par le développement de saules accompagnés de quelques aulnes; on trouve par ailleurs un cortège d'aquatiques de zone profonde ; sur les coteaux apparaît un cortège prairial. Soulignons qu'un groupement de côte sableuse existe à proximité du lieu de sondage. Pour ce qui est de la végétation forestière, c'est l'association Quercus, Pinus, Tilia qui prend le relais de la corylaie des niveaux sousjacents.

Un peu plus haut dans la colonne (la zone $\mathrm{h}$ : $416 \mathrm{~cm}-391 \mathrm{~cm}$ ), la courbe de AP/NAP se maintient aux environs de $80 \%$ de pollens d'herbacées. Ce constat est très certainement lié à la proximité de la mer. On note par ailleurs la disparition de la saulaie détectée dans les couches antérieures; la zone humide présente toujours des endroits profonds, mais on y trouve davantage de taxons de tranches d'eau moins profondes; les formations forestières sont composées de Quercus, Corylus, Pinus, Tilia et Ulmus.

Enfin, la zone i $(391 \mathrm{~cm}-331 \mathrm{~cm})$, qui pourrait couvrir le III $^{\mathrm{e}}$ millénaire av. J.-C. (et non le Néolithique moyen dans la division terminologique proposée par L. Gaudin), est marquée par le développement des Chénopodiacées ainsi que par la présence de quelques kystes de dinoflagellés (appartenant probablement aux cortèges de slikke et du schorre) qui signent une entrée d'eau de mer dans la zone humide.

Un des intérêts d'une telle étude à proximité du lieu de la découverte des haches et des stèles submergées est probablement de pouvoir estimer un peu plus précisément que de coutume l'éloignement du rivage, l'existence d'une zone humide au temps des témoins 
de cette occupation humaine étant désormais bien attestée autant par l'analyse des pollens que par celle des sédiments enfouis. Une première tentative de corrélation altimétrique entre les différents résultats déjà obtenus des tourbes situées sur le pourtour de cette Petite Mer permet d'ores et déjà de situer le dépôt des haches et l'ouvrage de stèles en rapport avec une séquence en partie contemporaine comme celle de Kerpenhir (Visset et al., 1996) en Locmariaquer (tabl. 4). Quatre datations obtenues sur les tourbes et les sédiments sur la plage de Porh Fetan ajoutent de nouveaux repères (tabl. 4) mais seront commentées avec nos collègues géologues dans un autre article relatif à ces variations du niveau marin. L'exercice est difficile, on le sait, car de multiples interactions régissant le trait de côte (les courbes de niveau des cartes marines s'établissent à partir des sédiments superficiels récents, fonds au surplus privés des formations périglaciaires déblayées au fur et à mesure de la montée des eaux) et les indices fiables sont trop peu nombreux; ces variations sont la somme de facteurs eustatiques, glacio-hydroisostatiques et tectoniques qu'il est toujours délicat de

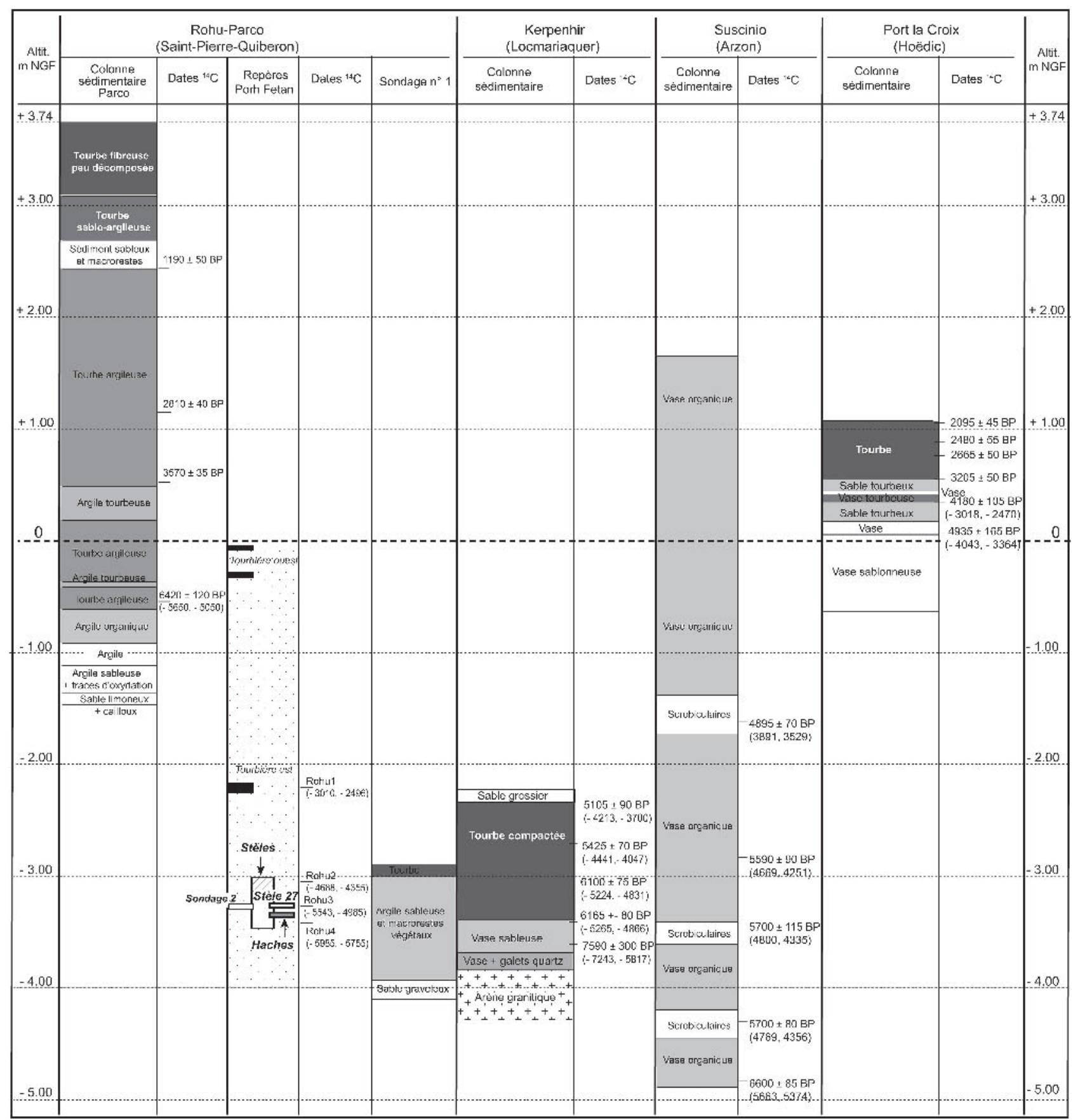

Tabl. 4 - Colonnes sédimentaires observées à l'occasion d'analyses polliniques en tourbières sur le littoral morbihannais (d'après Delalande et al., 2004; Gaudin, 2004; Visset et al., 1996) (DAO S. Cassen et S. Poirier).

Tabl. 4 - Sedimentary columns observed (for pollen analyses) in peat bogs on the Morbihan sea shore (after Delalande et al. 2004; Gaudin 2004; Visset et al. 1996) (CAD S. Cassen and S. Poirier). 
confronter aux témoins archéologiques submergés dans des tourbes aux compactions variables (Antonioli et al., 2007). La mise en évidence récente et précise du système des vallées incisées au sein même de cette mer intérieure (à nos yeux le Mor Bihan proprement dit, et non le Mor Bras si communément accepté depuis le $\mathrm{XIX}^{\mathrm{e}}$ siècle, qui désigne en réalité la vraie «grande mer» après le cordon protecteur des îles et des Chaussées) sera un paramètre essentiel pour estimer les surfaces progressivement couvertes par l'océan transgressif (Proust et al., 2001; Menier, 2004; Menier et $a l ., 2006$ et à paraître). L. Gaudin a cependant proposé une estimation du trait de côte au Néolithique en couplant le tracé des isobathes et les courbes du niveau marin (Larsonneur, 1977; Ters, 1973; MorzadecKerfourn, 1974). La lecture de ces courbes indique un niveau marin plus bas d'environ 8 à $10 \mathrm{~m}$ pour la période qui nous intéresse; le marnage actuel de la côte morbihannaise étant de $5 \mathrm{~m}$, le niveau des plus hautes mers de vives eaux est donc placé à l'isobathe de $-5 \mathrm{~m}$ NGF des cartes actuelles.

Nous retiendrons enfin des informations tirées du sondage l'absence de kystes de dinoflagellés dans les spectres polliniques contemporains des dépôts de Porh Fetan/Petit Rohu, qui ne plaide évidemment pas pour une communication entre les eaux du marécage et les eaux de mer. En revanche, le groupement de côte sableuse est identifié; il est donc fort probable qu'un cordon dunaire a existé, conclut L. Gaudin, retenant les eaux du marécage et faisant barrage à la pénétration marine. C'est d'autant plus vrai maintenant que nous savons que des niveaux tourbeux et vaso-tourbeux sont encore observés à $500 \mathrm{~m}$ à l'est du lieu du sondage. En cela, l'estimation de notre collègue quant à l'extension vers l'est de la zone humide au cours du Ve millénaire s'avère particulièrement juste.

\section{L'environnement archéologique}

Pour mieux illustrer autant qu'appuyer le caractère exceptionnel de la découverte du Petit Rohu, nous traiterons, ici encore de manière assez rapide, de l'intégration de ces objets au sein des contextes et vestiges archéologiques plus ou moins comparables dans le même secteur géographique, avant d'entrevoir les comparaisons offertes en Morbihan et dans l'Ouest de la France en termes de topologie des dépôts de haches et leur rapport éventuel aux stèles.

\section{La presqu'île de Quiberon}

- Outre les découvertes de lames de silex et autres «poteries des dolmens» sous les tourbes enlevées en bordure ouest du marais de Parco (Lavenot, 1888, p. 124), ou encore les «coffres » indéterminés observés par l'abbé Lavenot lors du creusement du sémaphore voisin de Quiberon (id., p. 125), le premier gisement sur lequel nous devons porter toute notre attention est bien entendu la plausible tombe de Saint-Julien, en Quiberon (Gaillard, 1892b; Mortillet, 1907; Marsille,
1927 ; Le Rouzic, 1965), située sur la hauteur au sud du marais, à proximité d'un menhir affaissé de près de 5 m de long (er Men Guen) et à 900 m de l'alignement de stèles et du dépôt du Petit Rohu. Deux grandes haches polies et quatre bracelets en roches «vertes» ont été recueillis en 1886 sous une «grosse pierre» lors de la construction du fort Saint-Julien, à côté d'un moulin édifié sur un «dolmen» ruiné, terme désignant à l'époque tout type de structure funéraire à orthostates (Rialan, 1924, p. 58). Une des lames polies est en éclogite alpine $^{7}$ (fig. 12), qui provient également des carrières néolithiques du mont Viso en Italie (inédit); elle fut déjà sollicitée, en raison de sa forme étroite et très allongée (mais sans réelle superposition avec le modèle gravé), dans un processus de reconnaissance des gravures de haches emmanchées sur un orthostate de Runesto (Plouharnel, Morbihan) (Boujot et al., 2000) ; mais la nature pétrographique double et bicolore de la roche d'origine, intentionnellement travaillée pour offrir ce partage longitudinal symétrique de la lame, fut également convoquée dans un modèle interprétatif plus général où le dualisme structural est adopté comme principe directeur (Cassen, 2000a).

- Le second point d'ancrage digne d'intérêt est le tumulus anciennement exploré (1820) sur le territoire de Quiberon (Mortillet, 1907; Marsille, 1927), mal localisé à l'époque mais dont l'emplacement vient d'être probablement retrouvé près du hameau de Kervihan (Er Drefigny en Saint-Pierre-Quiberon) (fig. 1). Il s'agit d'un monument à la morphologie classique dans la région, trapéziforme, orienté nord-sud, de $32 \mathrm{~m}$ de long pour une largeur en façade de $15 \mathrm{~m}$ et $9 \mathrm{~m}$ en son extrémité nord; dans le tiers inférieur et au centre du tertre, une dalle dans une dépression marque l'emplacement plausible d'une tombe, mais également une fouille ancienne. Quoi qu'il en soit de ce tertre, des deux bracelets ou anneaux extraits en 1820, seul l'individu en calcaire a été fort opportunément ramené à l'actualité des recherches (Pailler, 2007). Un des bracelets est morphologiquement identique à un des individus de Saint-Julien. Le matériau «calcaire» fin, réputé étranger à la région métamorphique - mais attesté sur place sous la forme grossière du calcaire coquillier présent à la base des tourbes et sédiments du bassin éocène de Parco (Durand, 1960) -, est pourtant présent sous l'aspect d'un petit bloc importé $(15 \mathrm{~cm})$, très érodé, dans le sol enterré de la Table des Marchand («paléosol»), où furent d'ailleurs récoltés 3 tessons VSG/ASP (décorés au peigne pivotant) d'un récipient «dégraissé» à l'aide de calcaire (Querré, à paraître), une totale anomalie parmi les 35000 tessons Castellic trouvés en fouille.

- À $1200 \mathrm{~m}$ au nord du Petit Rohu sont établis les alignements du Moulin (Mahé, 1825 ; Gaillard, 1892b), notre troisième point de comparaison immédiat, pour lesquels la démonstration a été faite qu'ils formaient une seule unité architecturale avec, $200 \mathrm{~m}$ plus bas, les dix files parallèles de stèles submergées découvertes sur l'estran et le platier rocheux (Cassen et Vaquero Lastres, 2003b). C'est au pied et au sud de la plus grande stèle du site ( $8 \mathrm{~m}$ de long; $\mathrm{n}^{\circ} 1$ [AL]) (id. p. 127) n'émergeant jamais totalement, même aux plus 


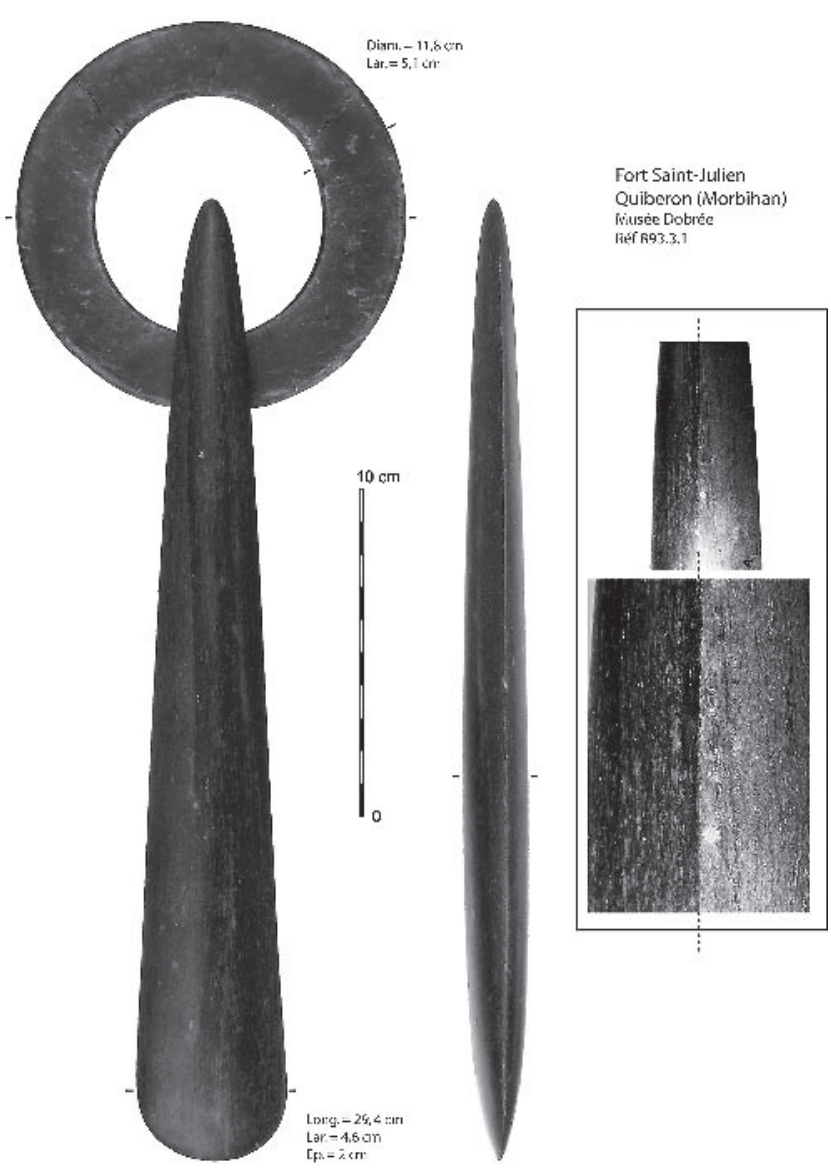

Fig. 12 - Lame polie en éclogite et bracelet en serpentinite du dépôt du fort Saint-Julien en Quiberon; vues de détail sur la partition volontaire en deux zones longitudinales symétriques tirant profit d'un contraste naturel de couleur dans la roche (musée départemental Dobrée, Nantes, $\mathrm{n}^{\text {os }}$ 893-3-1, 893-3-2; clichés H. Neveu-Derotrie; DAO S. Cassen).

Fig. 12 - Polished eclogite blade and serpentinite bracelet from the Fort Saint-Julien deposit, Quiberon; detail views of the deliberate division in two symmetrical longitudinal zones benefitting from a natural colour contrast in the rock (Dobrée Museum, Nantes, nos. 893-3-1, 893-3-2; photos H. Neveu-Derotrie; CAD S. Cassen).

basses eaux extraordinaires, que des pêcheurs à pied découvrirent en 2006 une lame de hache polie, découverte qu'ils portèrent opportunément à notre connaissance, car informés de la nature du site à la suite de la parution des Marches du Palais $^{8}$. Le matériau qui semblait en première approximation devoir être une fibrolite du nord-Finistère, gisements de la région de Plouguin (Pailler, 2007), s'est avérée être après analyse spectroradiométrique une jadéitite alpine (spectres Carn_130 et 131). La pièce paraît utilitaire (hache de type Chelles à section ovalaire), mais le poli poussé est bien conservé, accrochant même la lumière, ce qui atteste de l'existence d'un enfouissement protecteur; le tranchant a été repris après cassure sur angle, ou alors cette dissymétrie ne résulte que de la morphologie initiale du bloc de matière première, difficile à travailler. La configuration de l'espace environnant est ici directement superposable à celui de Petit Rohu/Porh Fetan, puisque l'ouvrage de stèles est disposé au nord et en bordure d'une ancienne zone humide, là encore développée derrière un cordon dunaire formant barrage.
Le parallèle devait être encore plus frappant quand L. Marsille signale des «menhirs tombés dans la tourbe» et que lui-même y récolte en 1910 «une belle ébauche de hache néolithique ${ }^{9}$ (Marsille, 1911 et 1930, p. 6), dont le procès-verbal du bulletin de 1956 indique qu'elle fut trouvée au pied d'un menhir; une tourbe sous-marine et des menhirs aujourd'hui disparus ou invisibles sous le sable de la plage.

- Au fond du marais de Parco vers l'ouest et sur l'exacte zone de partage orographique entre Côte sauvage et l'intérieur de cette vallée, un alignement de 40 menhirs est mentionné par l'abbé Collet (Closmadeuc, 1868); il n'en restait plus que 4 en 1888 (Lavenot, 1888); ils ont aujourd'hui disparu ${ }^{10}$. Au pied d'un de ces menhirs, à $50 \mathrm{~cm}$ de profondeur, l'abbé Collet recueillit une poterie bien enregistrée au musée de la Société polymatique à Vannes (n 418$)$, mais restée jusqu'ici inédite ${ }^{11}$ (Cassen, à paraître). Il s'agit d'un vase Castellic, de couleur brun-noir dans sa partie supérieure, brun clair sous le point d'inflexion et de cette même couleur à l'intérieur; le traitement de surface est altéré mais dut être très soigné; le décor opéré sur le col, de cannelures à peine marquées, consiste en deux motifs ondulés et croisés sur lesquels s'inscrit un motif en croissant, pointes tournées vers le haut; une cannelure large marque le diamètre maximum du vase. C'est un nouvel exemple, sur un site singulier, d'une application sur céramique d'un motif de l'art des stèles (voir le morceau de disque, partie concave également tournée vers le ciel, de la stèle de chevet de la Table des Marchand, face postérieure) (Shee Twohig, 1981; Boujot et al., 1998).

- Enfin, mentionnons, au nord de la commune de Saint-Pierre-Quiberon, la découverte ancienne par l'abbé Lavenot d'une hache en jadéite au lieu-dit Beg Port Blanc à Portivy, non pas dans la tombe à couloir explorée par Le Rouzic en 1901 mais à un autre endroit de la carrière de sable dont l'exploitation a malheureusement détruit nombre de vestiges, notamment des coffres funéraires (Le Rouzic, 1965). Et au sud de la presqu'île, dans la tombe indéterminée (en coffre ?) de Roch Priol, non loin d'un grand menhir couché sous la dune, une hachette en jadéite de type Chelles $(2,98 \times 1,2 \times 0,76 \mathrm{~cm})$ «admirablement façonnée et polie », «accompagnée d'une fort belle lame en silex » (Closmadeuc, 1892; Gaillard, 1892a), mais également d'une pendeloque en jadéite et de deux hachettes pendeloques en fibrolite ( $n^{\text {os }} 72945$ et 72750 de la collection P. du Châtellier conservée au MAN).

\section{L'enfouissement dans un marais}

Il semble maintenant admis que les quatre grandes haches en jadéitite ont été «plantées » dans un milieu argilo-tourbeux accumulé au pied d'un pointement granitique. Le marais est le milieu par excellence assurant une transition entre des états, entre deux mondes; nous avons ainsi convoqué cet espace séparateur pour expliquer la répartition des contextes funéraires et domestiques de part et d'autre du marais Er Varquez en Erdeven, ou encore l'immersion des beaux 
instruments polis (Cassen, 2000a). Cette pratique d'enfouissement des lames de haches (taillées, polies) dans un milieu humide est en effet rapportée par plusieurs découvertes européennes (Pétrequin et al., 2005a; Wentink, 2008), à commencer par une des plus fiables, en Angleterre, celle de la lame en jadéitite trouvée auprès d'un chemin de bois à Sweet Track Glastonbury dans les Somerset Levels (Coles et al., 1974), déposée entière et sans manche au bord de ce chemin qui a pu être précisément daté par dendrochronologie (38073806 av. J.-C.), confirmé par plusieurs datations directes sur céramiques (Berstan et al., 2008). Pour l'Armorique-sud, on pourrait citer la douzaine de haches polies extraites d'un dépôt dans une vase tourbeuse à Damgan (Morbihan), dégagées par la seule force des vagues (Marsille, 1930) et le dépôt de 7 lames de haches - dont une «blanchâtre » à talon perforé - recueillies en bordure du marais de Brière (Ust à St-André-des-Eaux, Loire-Atlantique) (Lisle du Dreneuc, 1882). Nous pourrions faire également mention de la pratique semblable des dépôts de galets marins allongés, bruts, dans ce même marais de Brière (la Grande Perrière à La Chapelle-des-Marais, Loire-Atlantique) (Lisle du Dreneuc, 1903) pour la similarité de l'intention qui s'étend, d'ailleurs, dans l'Ouest de la France, à l'ensevelissement de ces galets rassemblés au pied des stèles ou au contact des défunts, et ce depuis la fin du Mésolithique (Cassen, 2000b; Large, 2008).

Les stèles elles-mêmes présentent aussi la particularité remarquable d'être implantées et souvent enfouies dans un terrain bas colmaté, à l'image d'architectures de ce type connues dans de semblables environnements, mais à l'intérieur des terres (marais Er Varquez en Erdeven, Morbihan; marais de Brière et de Mesquer, Loire-Atlantique; marais de Béganne, Ille-et-Vilaine, etc.).

\section{L'accompagnement funéraire}

C'est le plus populaire des contextes archéologiques, car il a fait la renommée des tombeaux dits carnacéens dès leurs premières explorations. En impressionnantes accumulations (Tumiac, Mané er Hroëck, Saint-Michel) ou en dépôts plus isolés (Mané Hui, Er Grah, Mané er Ouah Tihir), les lames polies en roches alpines subjuguent les découvreurs et tous les commentateurs par leur forme, leur toucher, leur couleur, leur éclat. Les bris volontaires en deux ou trois fragments (Mané er Hroëck, Saint-Michel), l'acharnement parfois observé sur le tranchant (Mané er Hroëck), partie active et valorisée de l'arme/outil anéantie au sein même de la tombe (Mané Hui), confortent l'intuition que ces objets ne peuvent survivre à leurs détenteurs. C'est bien ce matériau rare et valorisé appliqué aux objets nouveaux, cet investissement démesuré en temps d'extraction, transferts, surpolissage qui ont en outre conduit à les reconnaître comme «divinités » en substance (Closmadeuc, 1873), objets consacrés à des puissances surnaturelles (Pétrequin et al., 2006a et b), ou désignés comme armes «magiques» (Cassen, 2005), mais surtout comme «objets-signes» dans l'affirmation des inégalités sociales aux commencements du Néolithique dans l'Ouest de la France, aux côtés de l'invention architecturale monumentale et ostentatoire, ou encore d'autres objets importés puis imités, provenant parfois de territoires encore plus éloignés que les Alpes, au beau milieu de l'aire d'apparition de la première métallurgie européenne (Cassen, 1991 et 2003 ; Boujot et Cassen, 1992).

\section{La déposition par couple}

Le positionnement souterrain par couple de lames polies attesté au Petit Rohu est un fait avéré dans la littérature, parfois même objet d'une recherche spécifique (Bordreuil, 1966), mais qui n'a été que rarement observé ces dernières décennies, a fortiori pour ces objets en roche alpine. Nous en rappelons quelques occurrences sur la carte régionale (fig. 13), pour des lames de diverses dimensions et sur des matériaux plus souvent régionaux (en bordure du marais maritime de Conleau à Vannes, Morbihan - Rollando, 1966; la Grie dans l'île de Noirmoutiers, l'îlot du Loisson à SaintHilaire-de-Riez et le Fief des Barres à Olonne, Vendée - Piet, 1863, Baudouin, 1914; la Rivière à PortSaint-Père et Launay à Vertou, ainsi que Montbert (sans précision) en Loire-Atlantique - Lisle du Drennec, 1882; Marionneau, 1863; Billard, 1932). Ce geste et cette intention sont parties intégrantes d'une représentation collective dont l'inscription dans la pierre n'est sans doute pas la moindre, à commencer par certains orthostates de la tombe à couloir de l'île de Gavrinis (Larmor Baden, Morbihan) où les haches jumelles, de morphologie «carnacéenne», gravées en pure isométrie (symétrie en réflexion d'axe et symétrie alterne ou inverse), côtoient les lames isolées ou encore regroupées par 3 et $4^{12}$. Ces appariements ont pu être rapprochés du processus technique de sciage à l'origine de ces longues lames obtenues dans une matière aussi dure (Lukis, $1848^{13}$; Le Roux, 1985 ; Cassen et Pétrequin, 1999; Pailler, 2005); on peut également les soumettre au principe anthropo-cognitif évoqué précédemment suivant lequel ces couples de haches participent pleinement du rapport fondamental à l'altérité où jumeaux divins et effets miroirs sont un des moteurs du fonctionnement du monde quand ils ne sont pas acteurs à son origine même (Cassen, 2000a). Dès le Néolithique en Europe de l'Ouest, doubles crosses, dolmens doubles, orthostates fendus en deux, vases à double embouchure, figurines humaines ou oiseaux bicéphales, couple d'animaux sacrifiés, menhirs doubles, doubles boutons par paires sur céramiques, alignements doubles, etc., répètent à l'infini un schéma radical.

\section{L'ensevelissement vertical}

Que ces lames du Petit Rohu aient été plantées verticalement en terre, le tranchant tourné vers le ciel, parties actives face à face, au point d'avoir blessé la main qui les a ramenées à la lumière, n'est pas une intention anodine; inutile d'y insister pour le moment. 


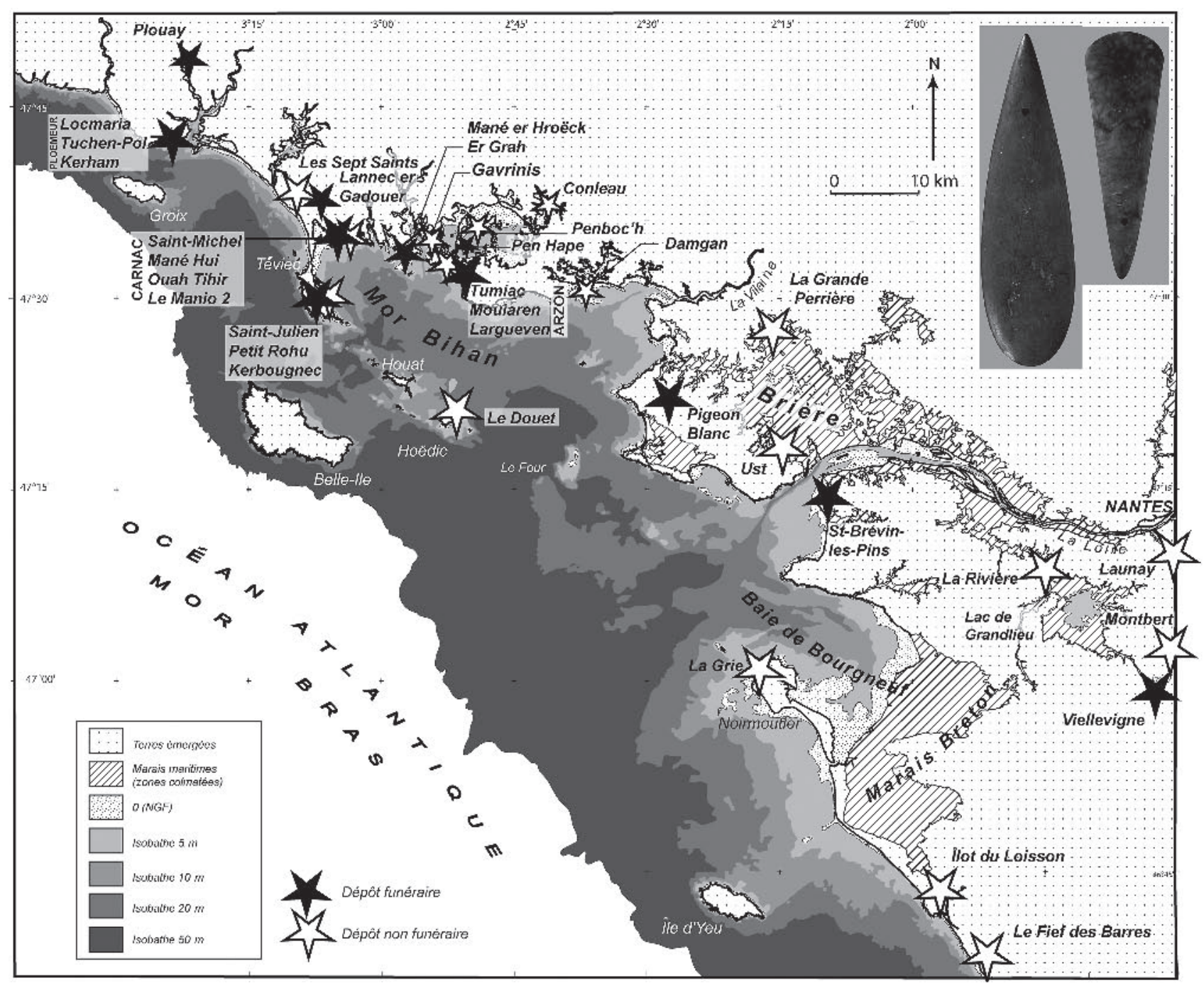

Fig. 13 - Localisation de quelques sites principaux mentionnés dans le texte, dépôts de haches; en vignette, lame inédite de type Durrington au talon perforé provenant de la presqu'île de Rhuys, Morbihan (36 cm, musée Dobrée, Nantes, $\mathrm{n}^{\circ}$ 853-14-1) et lame perforée du Petit Rohu (24 cm) (clichés H. Neveu-Derotrie; DAO S. Cassen).

Fig. 13 - Location of the main sites mentioned in the text, deposits of axes; in box, new blade of the Durrington type from the Rhuys peninsula, Morbihan (36 cm, Dobrée Museum,Nantes, no. 853-14-1) and perforated blade from Petit Rohu (24 cm) (photos H. Neveu-Derotrie; CAD S. Cassen).

C'est en tout cas une disposition qui, là encore, est d'un emploi universel (É. Patte, dès 1954, soulignait l'identité de traitement des haches verticales entre Danemark et Morbihan) et l'on pourra souligner, dans la région, les lames en roches alpines du fameux caveau SaintMichel (Carnac) (Galles, 1879), le dépôt en coffre du Mouillarien/Bernon (ou Vouillarienn, mais en réalité Mouiaren) en Arzon (Herbaut, 2000), la hache des Sept Saints en Erdeven trouvée plantée dans l'argile du talweg humide de Poumen (Le Rouzic, 1927), les haches de Kerham en Ploemeur où le découvreur, F. Le Dessert, signale leur dispersion sur 5 à $6 \mathrm{~m}^{2}$, avec «la partie tranchante en terre et le bout pointu en l'air» (archives inédites, musée de Carnac) ou encore, dans la masse du tertre 2 du Manio en Carnac, les cinq lames polies usagées plaquées sur une face de la stèle gravée érigée à l'extrémité orientale d'un des deux coffres du monument (Le Rouzic et al., 1922; Bailloud et al., 1995 ; Boujot et Cassen, 1997).

\section{Le rapport aux stèles}

Ce dernier exemple met en lumière un rapport de contiguïté topographique autant que sémantique entre un objet, la lame de pierre extraite, mise en forme, polie, parfois marquée (nervures) et plantée au sol, et la roche verticalisée dans un environnement donné, elle-même extraite d'un substrat affleurant et parfois mise en forme et marquée. Au Manio 2, nous l'avons dit, cinq lames polies utilitaires - dont une en fibrolite (sillimanite), probablement finistérienne -, tranchants vers le ciel, furent accolées à la face d'une stèle gravée de cinq serpents ondulants à la verticale, l'ensemble étant couvert par la masse d'un tertre; à toucher cette stèle, un coffre funéraire est fermé d'une dalle également gravée, mais d'une hache emmanchée où l'on remarque une très longue lame étroite à talon pointu proche de l'individu du fort Saint-Julien évoqué dans les paragraphes précédents. Ces relations structurales 
ont été rapprochées des découvertes de Lannec er Gadouer et des rapports similaires observés à Gavrinis (Cassen, 2000a); la lame en sillimanite plantée au pied de la stèle submergée $n^{\circ} 21$ du Petit Rohu participe du système pressenti (fig. 14). Récemment, la fouille d'une brève file de stèles au Douet à Hoedic (Morbihan) a permis de recueillir une lame en fibrolite au pied du monolithe marquant l'extrémité orientale de l'alignement (Large, 2008); un foyer sur le sol contenant une céramique à décor de lignes poinçonnées et boutons au repoussé date l'ensemble par le ${ }^{14} \mathrm{C}$ dans la fourchette 4700-4500 av. J.-C. La découverte déjà évoquée par L. Marsille de l'ébauche de hache au pied d'un menhir de la tourbe de Kerbougnec, ou encore de la lame en jadéitite polie (fig. 15) au pied de la stèle 1 à l'extrémité de ce même ouvrage, un ouvrage architectural aussi imposant que celui du Menec en Carnac (Cassen et Vaquero Lastres, 2003b), reproduit la même configuration spatiale et structurale.

Hors de tout contexte géographique comparable, en étudiant la raison d'être de l'érection extraordinaire de stèles parfois gigantesques dressées au sommet d'une montagne sibérienne uniquement accessible en été $(1500 \mathrm{~m})$, nous avons pu rapprocher leur existence,
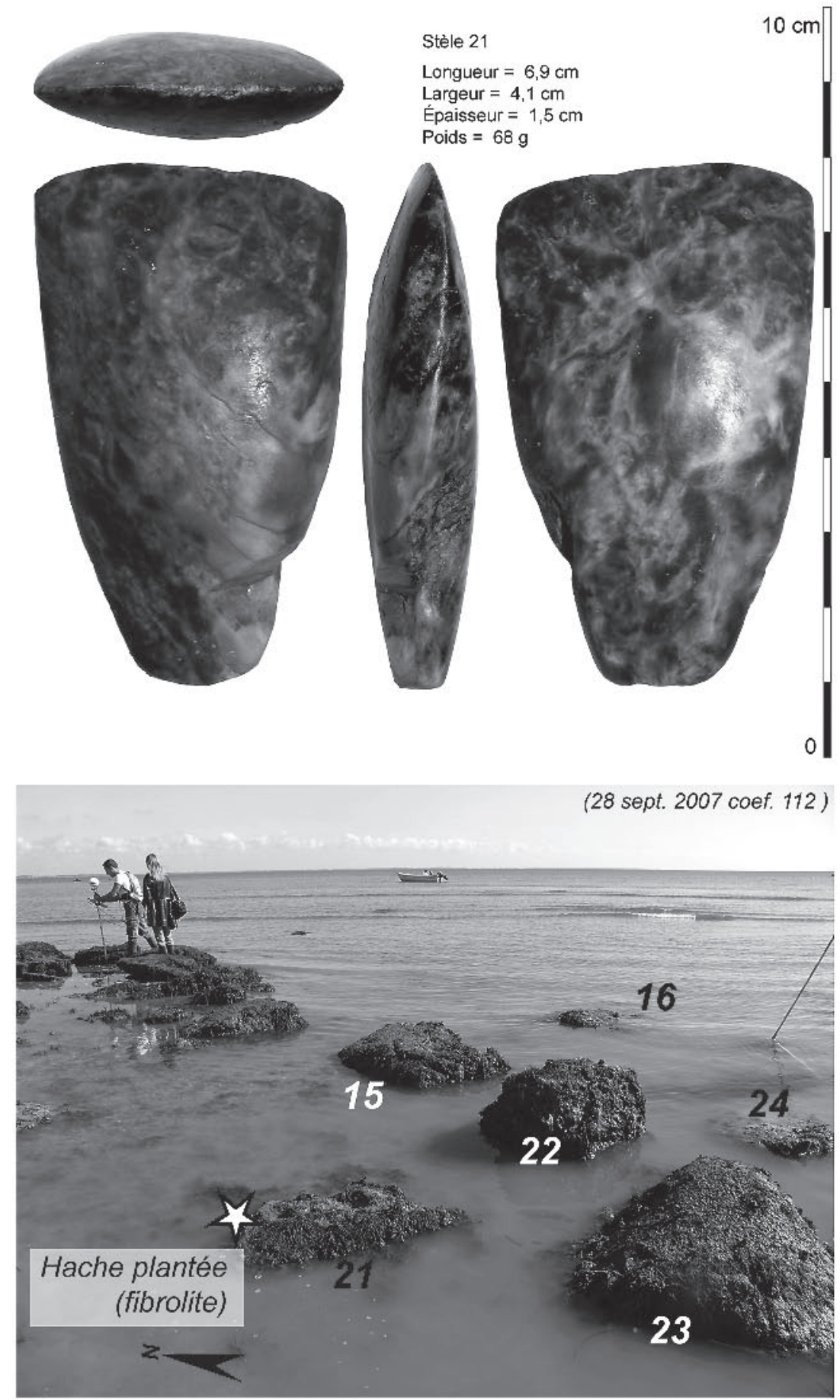

Fig. 15 (à droite) - La lame en jadéitite polie recueillie à la base de la plus grande stèle $\mathrm{n}^{\circ} 1$ (AL) des alignements submergés de Kerbougnec, Saint-Pierre-Quiberon; plan de distribution des monolithes, MNT avec une sélection de la file schématisée, orientée sur la grande stèle 1; profil de terrain et projection de l'ensemble des stèles enregistrées (d'après Cassen et Vaquero Lastres, 2003b) (cliché et DAO S. Cassen).

Fig. 15 (right) - Jadeitite polished blade found at the base of the largest stele no. $1(A L)$ of the Kerbougnec alignments, Saint-Pierre-Quiberon; distribution plan of the monoliths, DEM with schematized line directed towards the large stele 1; land profile and projection of all the recorded stelae (after Cassen and Vaquero Lastres 2003b) (photos and CAD S. Cassen).

Fig. 14 (à gauche) - La lame en sillimanite polie plantée à la base de la stèle submergée n ${ }^{\circ} 21$ (clichés et DAO S. Cassen).

Fig. 14 (left) - Sillimanite polished blade set at the base of submerged stele no. 21 (photos and CAD S. Cassen). 


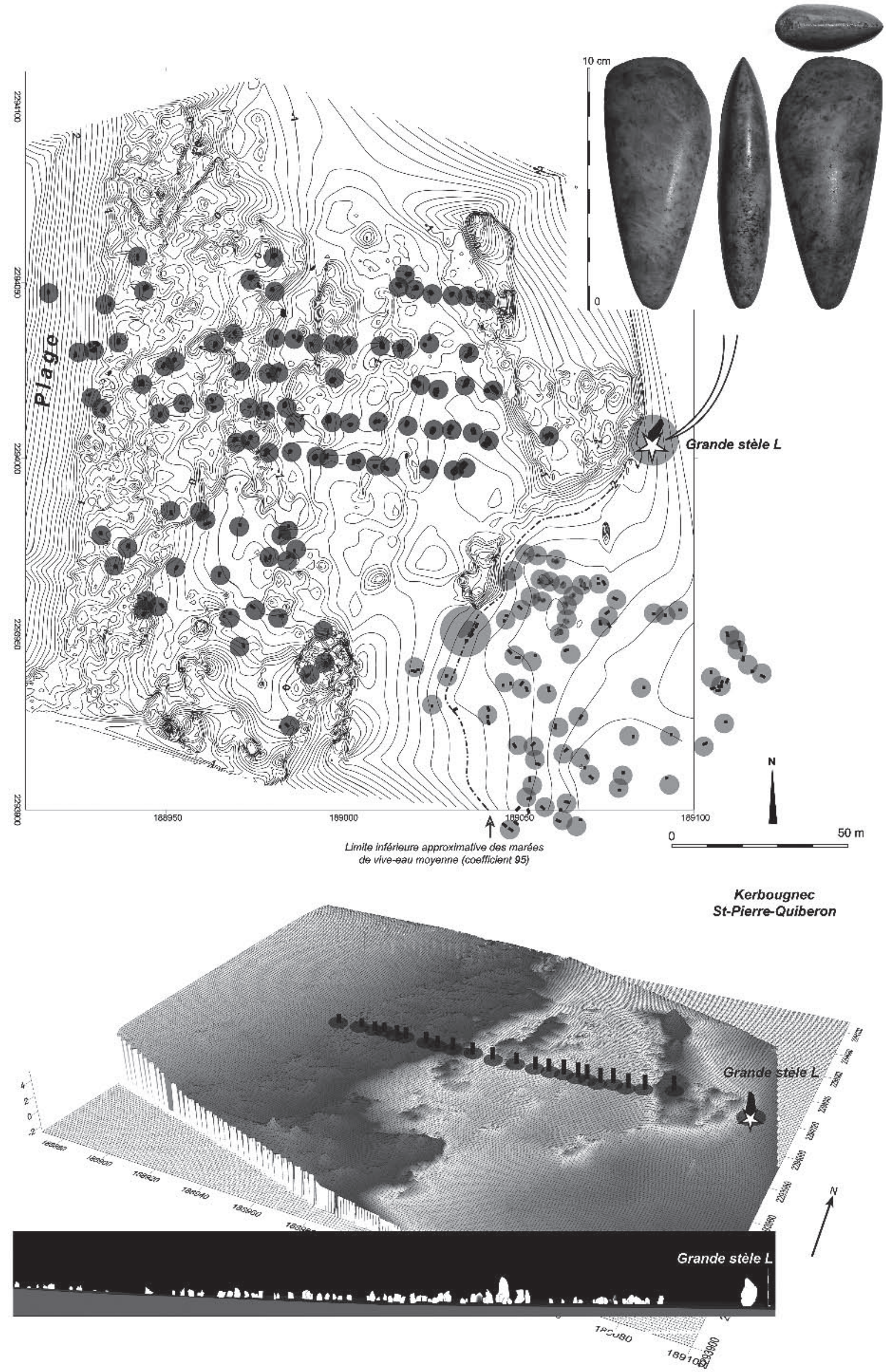


incongrue dans le schéma actuel de compréhension des milieux sépulcraux visibles uniquement en vallée, de l'extraction d'une roche verte et tenace (la vaugnerite; densité 3) en vue de la confection de lames de haches à une époque indéterminée mais qui pourrait être antérieure à l'Âge du bronze de ces régions. L'image des «ateliers» de hachettes en fibrolite d'Er Lannic en Morbihan, au contact direct d'au moins un des deux hémicycles de stèles, s'est alors tout naturellement imposée, d'autant mieux qu'un fait similaire était révélé au pied d'un autre alignement de stèles en bordure du lac de Neuchâtel (Le Rouzic, 1930; Cassen et al., 2006; Pétrequin et al., 2007; Grau Bitterli et Joye, 2007); les sites de Kermorvan (Le Conquet) et de Lannoulouarn (Plouguin) en Finistère peuvent participer du même schéma de compréhension (Pailler, 2007). Des faits paraissant plus anecdotiques dans la littérature pourraient alors être réévalués dans ce sens, comme les deux haches en jadéitite plantées sur leur talon devant l'abri, en partie sépulcral, des Bérards à Lurs (Alpes-de-Haute-Provence), auprès desquelles une petite dalle $(40 \mathrm{~cm})$ est dressée, comprise comme «stèle aniconique» (Cotte, 1924).

Sans insister davantage dans cette voie, on soulignera néanmoins que l'aspect prédictif du modèle en construction s'est avéré juste dans le cas du Petit Rohu où nous annoncions avant l'intervention du 28/09/2007, à côté de la possibilité d'un milieu sépulcral, la plausible association avec un ouvrage de pierres dressées.

Un site particulier dans la partie armoricaine du Maine-et-Loire peut être alors mentionné pour mémoire et illustration de la problématique ${ }^{14}$. Une hache en «jadéite» fut en effet recueillie vers 1820 au pied de la grande stèle en granite $(6,2 \mathrm{~m}$ hors-sol, la plus haute du département) de la Bretellière à Saint-Macaireen-Mauges, un objet entré dans les collections SLA de Cholet dans les années 1880 ; la stèle est érigée au centre d'un alignement ruiné de plusieurs monolithes très espacés sur plusieurs centaines de mètres (Port, 1878; Gruet, 1967), une stèle sur laquelle P. Raux a récemment attiré l'attention des archéologues en raison de l'immense gravure d'un chevron vertical terminé en volute qui a permis d'assimiler le tout à un serpent (Raux et Joussaume, 2000; Scarre et Raux, 2000; Joussaume, 2002; Joussaume et Raux, 2006). Ajoutons, pour notre part, l'existence toute proche de trois dépôts de couples de lames polies en «diorite» (catalogue SLA 1884-1887) (Desmazières, 1925), tout d'abord sur la commune limitrophe de Saint-Andréde-la-Marche (sans localisation précise; la stèle est d'ailleurs en exacte limite entre ces deux territoires), ensuite sur l'autre commune également voisine de La Séguinière (sans localisation), enfin sur la commune suivante le long de la rivière Moine, Cholet-La Boucherie, bref autant de dépôts suffisamment exceptionnels en soi pour que leur situation si rapprochée de la stèle de la Bretellière n'occasionne une nouvelle correspondance avec la découverte du Rohu ; mentionnons également pour être complet dans cette même région, mais à une vingtaine de kilomètres au nord, le couple de haches, cette fois en roche alpine, trouvées «superposées » à la Gréfumière en Saint-Rémy-enMauges (Le Quellec, 1984).

La trace de la hache en «jadéite» s'est malheureusement perdue; il existait pourtant une longue lame $(22 \mathrm{~cm})$, d'un vert très sombre, au poli parfait presque miroitant, dans les collections du musée de Cholet que nous entretenions avec $\mathrm{M}$. Cottin au début des années 1970; une lame sans étiquette de provenance mais qui était la seule de la collection, parmi des centaines d'individus, à pouvoir correspondre au don fait à la société au XIX ${ }^{\mathrm{e}}$ siècle; C.-T. Le Roux, en 1975, à qui nous avions montré l'objet, penchait pour une chloromélanite ${ }^{15}$; il s'agissait d'une lame à bords droits équarris, au talon également équarri, le type Puy de la nomenclature ${ }^{16}$, autrement dit un objet appartenant à la fin de la séquence typochronologique.

Quoi qu'il en soit, la relation, semble-t-il vérifiée, entre une stèle et une lame en roche alpine enfouie à son pied doit désormais nous amener à réfléchir sur la catégorie des dépôts dits «sous dalle». Plusieurs cas de figures peuvent être en effet envisagés pour interpréter ces haches et bracelets couverts d'un monolithe, en recherchant la possibilité qu'il ait pu s'agir d'une stèle chutée, ou bien replacée à l'horizontale...

- L'interrogation vaut pour des ensembles armoricains plus éloignés du littoral sud comme le dépôt d'un couple de haches (réputées être en jadéite mais qui ne le sont pas; cf. programme Jade) sous une roche, découvert sur l'îlot d'Herm au large de Guernesey (Kendrick, 1928);

- mais également pour la famille des «sépultures sous dalles » du Loiret (Les Marsaules, La Chaise, Les Fiefs, qui ne contiennent cependant pas de belles haches en roches alpines) (Simonin et al., 1997) dont la dalle en question est toujours largement sous-dimensionnée par rapport à la fosse et très surdimensionnée par rapport au corps curieusement disposé en limite du monolithe;

- une inadéquation observée à l'angle de la maison VSG du Haut Mée (Saint-Étienne-en-Coglès, Ille-etVilaine) (Cassen et al., 1998; Cassen et Vaquero Lastres, 2003a) où une pierre en granite de 1,20 m de long couvre, mais en partie seulement, une fosse étroite allongée (à la dimension d'un corps) à l'extrémité de laquelle une céramique VSG était écrasée, et dans laquelle fut découvert un couple de haches jumelles en sillimanite imprégnée d'ocre : le monolithe présente une extrémité entièrement piquetée qui plaide en faveur d'un ancien élément d'architecture (stèle), comme pousse à le concevoir, de surcroît, une fosse de calage implantée à moins d'un mètre de l'excavation finalement interprétée comme une sépulture;

- on se rappellera d'ailleurs que le dépôt de 24 lames polies en roches alpines au lieu-dit Largueven en Arzon (Morbihan) a été trouvé sous une pierre naturellement décrite par L. Marsille comme un «menhir», à tort ou à raison (Marsille, 1939; Herbaut, 2000);

- achevons avec les deux haches (176 et $164 \mathrm{~mm}$ ) à section ovalaire trouvées au pied du grand menhir la 
Chaise au Prêtre (au centre géométrique de Guernesey), en fait un menhir double puisqu'un bloc plus petit et cubique est planté au pied du premier monolithe, donnant la forme et le nom (Kendrick, 1928).

Les rapports étroits entretenus entre la hache polie et la stèle, qui couvrent l'ensemble du registre des représentations, entre verticalisation d'une puissance et anthropomorphisation de l'objet (Pétrequin et al., 2006b) - ce dernier syndrome étant un ensemble de signes et comportements dans lequel on se gardera de ne pas systématiquement tomber, tant est bien souvent forcée la reconnaissance de la pseudo-silhouette humaine, un processus cognitif plutôt classique chez l'homme (Cassen, 2007) - sont en conséquence une voie de recherche à explorer et en tout cas un argument pour renforcer la cohérence du gisement quiberonnais. Bref, nous sommes confrontés à un problème «total», comme nous aimons le qualifier, en abordant cet environnement archéologique dont l'interprétation des faits ne peut se suffire de la résolution d'un seul paramètre pour résoudre l'équation plus générale.

\section{La liaison roches alpines/sillimanite/variscite}

Les premières lames de haches polies du Néolithique le plus ancien sur le Massif armoricain sont avec fréquence tirées de la fibrolite/sillimanite (Cassen et al., 1998; Guesquière et al., 2001), un matériau difficile à travailler, qu'il faut scier comme la jadéitite (Pailler, 2007) et qui, avec régularité, accompagne en Bretagne les roches alpines dans la première moitié du V $V^{\mathrm{e}}$ millénaire; un matériau dont l'importance doit être aussi mesurée à la façon dont la péninsule Ibérique - Catalogne exceptée - rejette la circulation de ces roches en provenance d'Italie (fig. 16). Les provinces septentrionales d'Espagne, qui auraient pu être les premières tentées par ce phénomène de transferts, sont riches en gîtes et découvertes de lames polies en sillimanite (Domínguez-Bella et al., 2004) et en sources de variscite (Villalba et al., 1998); elles ont pu être pourvoyeuses de ces matières (un fait vérifié pour la variscite de la région de Zamora (El Bostal) et celle de Huelva, plus lointaine, aux frontières sud du Portugal (Encinasola) (Querré et al., 2008), en tout cas ce sont des régions (Galice, Nord-Portugal, Andalousie?) partageant avec l'Ouest de la France une représentation trop singulière pour être le fruit d'un simple hasard : un cétacé, le cachalot, de surcroît sur des stèles en réemploi au sein des tombes à couloir (Cassen et Vaquero Lastres, 2000 et 2004).

\section{CONCLUSIONS}

- La découverte de haches polies sur l'estran de Porh Fetan, dite plage du Petit Rohu en limite communale entre Saint-Pierre-Quiberon et Quiberon (Morbihan), en réalité sur le domaine public maritime de l'État, a bénéficié de circonstances locales et nationales très favorables pour assurer une bonne gestion administrative autant que scientifique et conservatoire (musée de Carnac ${ }^{17}$; traitement spécifique du secteur géographique par un agent du SRA; programmes ACR Table des Marchand et ANR Jade) (fig. 16).

- Le dépôt est dédoublé et consiste en deux couples de lames polies, distants d'une vingtaine de centimètres, plantés verticalement, tranchants au ciel, les deux plans transversaux formant entre eux un angle de $45^{\circ}$ dont le sommet serait dirigé vers le haut de la plage. Les tranchants émergeaient du sédiment argilosableux et argilo-tourbeux, à égale hauteur, mais devaient très probablement être surmontés par une couche de tourbe vraie de faible puissance $(6-10 \mathrm{~cm})$ couvrant à l'origine l'ensemble du secteur sous le sable marin, contraste de nature et de texture qui a permis que les fils si aigus du tranchant soient parfaitement conservés ainsi que le poli miroir, préservé sur la pièce $n^{\circ} 2$ (lame perforée), dont le suivi sur les deux faces marque la limite entre les contextes sédimentaires de même qu'il indique la pente du terrain.

- Le matériau rare est une jadéitite alpine, dont l'analyse spectroradiométrique démontre qu'au moins trois lames du dépôt sont issues d'un gîte identique. Les quatre haches ont été tirées des carrières du mont Viso, en Piémont (Italie).

- À une vingtaine de mètres au sud du lieu de dépôt des haches, parallèlement au rivage, une dalle enfouie dans le sable et le gravier est une stèle affaissée en vis-à-vis d'un affleurement granitique vertical, reproduisant à l'identique la configuration décrite pour la grande stèle $n^{\circ} 1$ de Kerbougnec, vaste complexe architectural sous-marin au nord du Beg Rohu.

- À près de $80 \mathrm{~m}$ au S-SE $\left(82^{\circ}\right)$ du dépôt, 41 blocs de granite se répartissent sur une aire graveleuse (sableuse en périphérie) de $200 \mathrm{~m}^{2}$, formant sur une vingtaine de mètres un alignement principal NNE/SSO de dalles couchées, excepté un individu trapu placé de chant, préservé en cette position à cause de son assise large. Sans confusion possible avec une construction de type pêcherie (visibles $800 \mathrm{~m}$ au sud au large de Saint-Julien) et présentant toutes les caractéristiques inventoriées sur les sites voisins (Kerbougnec à SaintPierre-Quiberon) ou régionaux (Kerdual à La Trinitésur-Mer), l'ouvrage est défini comme une barre de stèles dont il est difficile à l'heure actuelle d'affiner l'ordre architectural originel (file simple; files orthogonales, parallèles) ni même son emprise en raison de l'enfouissement des pierres, notamment en direction du dépôt. Vingt-six dalles furent reconnues et les levés réalisés en prospection terrestre par photographie verticale et GPS différentiel; les quinze autres furent confirmées ou découvertes en prospection sous-marine, quand 5 à $6 \mathrm{~m}$ d'eau couvrent le site à l'époque des vives-eaux.

- L'anse de Porh Fetan (le Port [de] la Fontaine) s'inscrit entre deux platiers rocheux et tire son nom d'un écoulement permanent d'eau claire en provenance de la zone humide préservée à l'ouest, en arrière d'un cordon dunaire formant le haut de la plage, supportant la route côtière, barrant une vallée qui traverse la presqu'île de part en part et dont l'extrémité amont du talweg est située à la Côte sauvage. Dès le $\mathrm{VI}^{\mathrm{e}}$ millénaire 


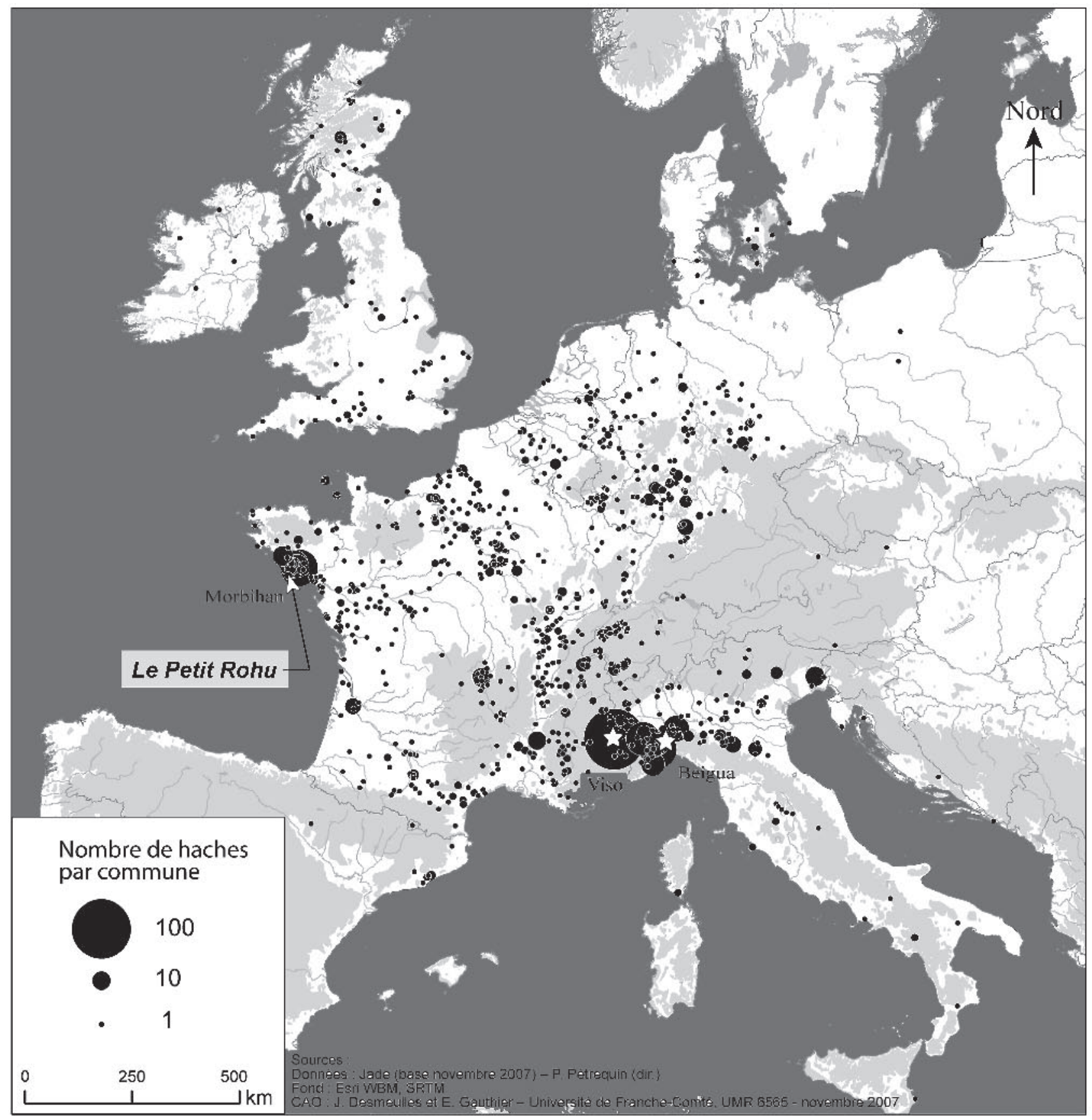

Fig. 16 - Répartition des grandes haches alpines en Europe occidentale, de longueur supérieure à $14 \mathrm{~cm}$. Les cercles sont proportionnels au nombre de haches dans chaque commune. Base de données JADE, P. Pétrequin dir. (état novembre 2007; fond : Esri WBM, SRTM; CAO J. Desmeulles, E. Gauthier).

Fig. 16-Distribution of the large Alpine axes in Western Europe, length over $14 \mathrm{~cm}$. The circles are proportional to the number of axes in each site. Data base JADE, P. Pétrequin dir. (state November 2007; data: Esri WBM, SRTM; CAD J. Desmeulles, E. Gauthier).

av. J.-C., l'influence marine est détectée dans les sédiments accumulés en fond de vallon, derrière un ancien cordon dunaire placé quelques centaines de mètres en contrebas de l'actuel. Au cours du Ve millénaire, au temps de l'enfouissement des lames polies actuellement situées à - 3,40 m NGF, le rivage est peu éloigné (aux alentours de $-5 \mathrm{~m}$ ), l'estran se situant à quelque $500 \mathrm{~m}$ de là, peut-être moins encore. Derrière ce probable cordon dunaire, le dépôt des haches s'effectue dans une zone humide, au pied d'un affleurement granitique remarquable où de longues dalles sont naturellement verticalisées dans le substrat, à la différence du platier qui découvre au nord et présente une orientation horizontale des bancs rocheux très érodés. Encore une fois démontré dans la région, l'affleurement rocheux participe du balisage du monde, interrompt la continuité de l'espace; ici comme ailleurs les rapports de l'homme avec le milieu naturel jouent le rôle d'objets de pensées; mais ici plus qu'ailleurs se forme le concept fondamental de la limite... Enfin, un barrage encore plus efficace de la vallée amène le développement, à une époque postérieure à déterminer sur 
l'échelle archéologique, d'une tourbe terrestre qui sera par la suite couverte d'un sol (ou de sablons) sur lequel seront développées des façons culturales révélées par des traces de labours croisés; ce sol est lessivé par la remontée de l'océan, la tourbe indurée plus résistante étant finalement recouverte par le sable marin. C'est l'érosion progressive du rivage qui emporte désormais ce placage de tourbe, découvrant les sédiments meubles sous-jacents.

Ces découvertes simultanées sont un nouvel et bon indicatif de l'exceptionnalité de la région en termes de vestiges archéologiques, notamment néolithiques, une région formant un véritable laboratoire à ciel ouvert. Les recherches peuvent y être menées en accord avec un modèle (cf. la découverte de l'alignement de Kerdual en adéquation avec le schéma interprétatif donné antérieurement au congrès de Porto) (Boujot et al., 1995), en s'inscrivant dans des programmes d'investigations (Table des Marchand/Er Grah; Lannec er Gadouer; corpus des signes gravés) et en accompagnant, autant que faire se peut, les interventions préventives (Kerdruellan).

Les alignements de stèles submergées, nouvelle catégorie de vestiges archéologiques en Morbihan ${ }^{18}$, doivent aussi leur découverte, et une liste de gisements chaque fois plus augmentée, à l'intérêt grandissant porté sur la question posée dans le cadre élargi du problème «Carnac», énigme historique s'il en est. La modélisation est en cours de construction; elle cherche ses moyens heuristiques autant que financiers là où elle est en mesure de le faire, mais sans doute pas là où nous pourrions nous attendre à les trouver. Quoi qu'il en soit, les vestiges du Rohu viennent ajouter une pièce significative à l'édifice conceptuel.

Il est en tout cas hors de doute pour les préhistoriens de ces régions qu'une surveillance accrue et spécifique, dictée par l'énorme pression foncière actuelle, sera un répondant très efficace, une attention semblable en nature à celle que $\mathrm{Z}$. Le Rouzic avait pu maintenir en son temps face au travail destructeur des carriers sur des monuments que ne protégeait plus la croyance populaire. Le devenir du site quiberonnais peut d'ailleurs être posé. Kerdual, que nous rappelions, est un exemple voisin récent où, au côté d'un alignement de stèles, un tertre gigantesque et sa tombe peuvent progressivement disparaître sous nos yeux par la seule action destructrice de l'océan. De fait, la fouille envisageable au Petit Rohu est un véritable problème en soi, autant technique que scientifique, et qu'il conviendrait de replacer plus généralement dans le contexte difficile des nombreuses priorités affectant cette région. En attendant, les coefficients médiocres des grandes marées prévues pour 2008 ne seront pas en mesure de nous permettre autre chose que de ponctuelles observations; gardons cependant l'espoir que les meilleurs chiffres annoncés pour 2009 autoriseront un temps d'accès plus allongé permettant de l'inscrire dans le cadre élargi d'une opération programmée mêlant le terrestre et le sous-marin.

\section{NOTES}

(1) Traduction : $\mathrm{D}^{\mathrm{r}}$ Alison Sheridan, que nous remercions encore une fois pour son aide précieuse.

(2) Près d'un an après cette découverte, une magnifique hache en jadéitite intacte sera recueillie en Erdeven, mais malheureusement aussitôt vendue à un antiquaire professionnel écumant avec patience les récoltes des amateurs et des agriculteurs régionaux, fort bien informé des prix exorbitants que peuvent aujourd'hui atteindre ces objets dans les salles des ventes... Il suffit d'ailleurs de comparer les entrées des haches de ce type dans les musées régionaux jusqu'aux années 1930 avec celles qui sont dénombrées depuis cette époque, entrées en réalité presque inexistantes alors que ces lieux n'ont jamais été autant visités, prospectés, bouleversés par l'aménagement du territoire.

(3) Le mot est issu de Park Geot en vannetais, qui est le champ réservé pour donner de l'herbe, ce qui est en effet toujours le cas (Ernault, 1919).

(4) Les opérations techniques, coordonnées par S. Cassen, ont été partagées de la manière suivante : photographies sur site : P.-A. Besombes, C. Boujot, S. Cassen, S. Hoba, O. Hulot, A. MacHale, S. Poirier, E. Vigier; sondages tarière pédologique manuelle : S. Cassen, D. Marguerie; levés ortho-photographiques des stèles : C. Boujot, S. Cassen, E. Vigier; levés topographiques GPS : T. Lorho; constitution SIG : F. Scalliet, D. Menier; prospections et relevés sous-marins : C. Dagneau, D. Dégez, E. Veyrat; prospections terrestres : C. Boujot, S. Cassen, C. Obeltz, E. Vigier; prises de vues sous-marines : Frédéric Osada, Teddy Seguin; DAO des relevés sous-marins: D. Dégez; DAO des relevés terrestres : S. Cassen, S. Poirier; photographies des objets : S. Cassen, H. Neveu-Dérotrie, H. Paitier; dessins des objets : S. Cassen, Y. Pailler, Y. Sparfel; spectroradiométrie des haches : M. Errera; cartographie : S. Cassen, F. Scalliet; suivi administratif : C. Boujot, C. Jablonski documentation : C. Le Gall, C. Obeltz; gestion des missions : M. Tostivint (Archeosciences, Rennes), I. Mouret (MSHE, Besançon).

(5) L'intervention s'inscrit dans plusieurs programmes scientifiques en cours d'exécution qui ont financé les différentes missions sur le terrain et en laboratoire :

l'action collective de recherche portée par le ministère de la Culture et de la Communication (ACR Recherches archéologiques à la Table des Marchand, Locmariaquer, Morbihan) et dirigée par S. Cassen (CNRS, univ. Nantes);

la prospection des contextes sous-marins en baie de Quiberon et golfe du Morbihan (géophysique, Lidar, sonar latéral, etc.) par des géologues (D. Menier et A. Baltzer dir., 2006-2008) à laquelle contribue l'archéologie préhistorique depuis deux ans (S. Cassen et S. Poirier), en prolongement des recherches de structures architecturales submergées (2001-2003) sur cette partie de la presqu'île de Quiberon; une campagne de validation des anomalies (monolithes) est d'ailleurs sollicitée auprès du DRASSM pour juillet et août 2009;

le programme JADE (Inégalités sociales et espace européen au Néolithique : la circulation des grandes haches en jades alpins) dirigé par P. Pétrequin (programme blanc ANR, MSHE de Besançon);

en outre, la constitution du SIG et la prise en charge de 4 datations ${ }^{14} \mathrm{C}$ a bénéficié des programmes de recherches (Dynamiques sous-marines) de D. Menier à l'université de Bretagne-sud (Vannes, IUP) et du programme pluridisciplinaire ATTP financé par l'université de Nantes (thème 2: Occupation des espaces littoraux de la Bretagne-sud à la Vendée du Ve millénaire av. J.-C. à nos jours, dirigé par S. Cassen); les photographies des objets ont été gracieusement fournies par le musée départemental Dobrée (CG 44) grâce à l'intervention de M.-H. Santrot, conservateur, dans le cadre d'un partenariat entre l'établissement et le LARA (Nantes), ainsi que par l'INRAP Grand Ouest.

(6) L'analyse spectroradiométrique en réflectance diffuse est non destructrice et permet de comparer les spectres obtenus sur des haches polies néolithiques avec les spectres des échantillons naturels de référence; les signatures caractéristiques de certains gîtes autorisent les comparaisons et les propositions d'attribution d'une hache à une origine minéralogique et géographique précise (Errera et al., 2007).

(7) Cet objet est conservé au musée Dobrée à Nantes; l'autre lame $(36,5 \mathrm{~cm})$ se trouve au MAN, dans la salle P. du Châtellier.

(8) Tous nos remerciements à Mme Simone Ansquer, mairie de SaintPierre-Quiberon.

(9) L'ébauche est enregistrée sous la référence RL 56.2.1 dans la réserve Saint-Symphorien des musées de Vannes $(\mathrm{P}=662 \mathrm{~g} ; \mathrm{L}=19,4 \mathrm{~cm}$; 
1 (tranchant $)=6,9 \mathrm{~cm} ; \mathrm{e}(\max )=4,.0 \mathrm{~cm})$. Décrite tout d'abord comme diabase, puis comme pyroxénite par L. Marsille, elle semble cependant proche d'une dolérite comme le type A.

(10) Z. Le Rouzic attribuera par erreur l'alignement de Kervihan au hameau de Keridanvel (Le Rouzic, 1965).

(11) Nous sommes encore une fois redevables envers M.-F. Le Saux, conservatrice du musée, et C. Le Pennec de nous avoir permis d'étudier ces éléments avec autant de facilité.

(12) Rappelons que le dépôt de 3 lames polies est également bien attesté dans la région : 3 haches en fibrolite regroupées en façade de Gavrinis, 3 lames en dépôt dont une en fibrolite et deux en pyroxénite à Penboch en Arradon, 3 lames en fibrolite superposées par leur face sous le plancher du caveau de Lannec er Gadouer, pour ne citer que des gisements connus (Gaillard, 1897; Marsille, 1921; Le Roux, 1985; Boujot et Cassen, 2000).

(13) "A celt lately found in Guernsey, composed of chert, has for some purpose or other been divided longitudinally. The operation was commenced by wearing out a narrow groove with a stone, or wood and sand, down to half its diameter on each side; then when worn nearly to meet the parts were broken, and the rough edges rubbed smooth and polished, leaving a slight groove on either side, giving the appearance of an intention of ornament, whereas it is the result only of the method used in reducing the stone to a proper form" (Lukis, 1848, p. 276).

(14) Une situation historique également remarquable puisque la zone est placée sur les Marches de Bretagne, du Poitou et d'Anjou (d'où Saint-André-de-la-Marche); dans les siècles passés, la région pullulait d'ailleurs de faux sauniers trafiquant le sel venant de Bretagne et traversant ici une limite très surveillée par les gabelous des XVII ${ }^{\mathrm{e}}$ et XVIII siècles. Que le seul alignement de stèles reconnu sur une aire géographique grande comme un département soit ici superposé à une frontière historique n'est sans doute pas le fruit d'une simple coïncidence (Cassen, à paraître)

(15) Roche alpine également définie par A. Damour, du grec khlaros « vert» et melas «noir».

(16) Ce que C.-T. Le Roux nous a confirmé et nous l'en remercions. Nous sommes également redevables à L. Epain d'avoir eu la gentillesse de rechercher cet objet dans les collections dont il est responsable à la Maison des sciences de Cholet.

(17) Les objets sont désormais conservés au musée municipal de Carnac, une convention ayant été signée entre la ville de Carnac et le DRASSM, convention de dépôt à long terme de collections de l'État. Le dépôt est consenti pour 5 ans et renouvelable par tacite reconduction. Le musée de Carnac est donc dépositaire mais non propriétaire.

(18) Kerdual (Carnac/La Trinité), Kerbougnec (Saint-Pierre-Quiberon), Kerpenhir (Locmariaquer), Petit Niheu (Belz), Nestadio et le Passage (Plouhinec), Park er Resteu (Nostang), le Grand Rohu (Saint-Gildas-deRhuys).

\section{ABRÉVIATIONS DANS LE TEXTE}

ACR : action collective de recherche.

ANR : Agence nationale de la recherche.

ATTP : Apprentissage, temps, territoires, patrimoines (programmes de recherches en sciences humaines, université de Nantes).

ADRAMAR : Association pour le développement de la recherche en archéologie maritime.

CG 44 : conseil général de Loire-Atlantique.

OCM : $0 \mathrm{~m}$ des cartes marines.

DRASSM : département des Recherches archéologiques subaquatiques et sous-marines.

IUP : Institut universitaire professionnalisé (Vannes).

LARA : Laboratoire de recherches archéologiques (Nantes), exLaboratoire de Préhistoire et Protohistoire de l'Ouest de la France, depuis le $01 / 01 / 08$.

Pbm : plus basses mers.

SLA : Sciences, lettres et Arts (Cholet).

SHOM : Service hydrographique et océanographique de la marine.

TDM : Table des Marchand.

UBS : université de Bretagne-sud (Vannes, Lorient).

\section{RÉFÉRENCES BIBLIOGRAPHIQUES}

ANTONIOLI, F., ANZIDEIB M., LAMBECKC K., AURIEMMAD R. GADDIE D., FURLANIF S., ORRU P., SOLINASH E., GASPARII A., KARINJAJ S., KOVAC V., SURACE L. (2007) - Sea-level change during the Holocene in Sardinia and in the northeastern Adriatic (central Mediterranean Sea) from archaeological and geomorphological data, Quaternary Science Reviews, vol. 26, p. 2463-2486.

BAILLOUD G., BOUJOT C., CASSEN S., LE ROUX C.-T. (1995) Carnac. Les premières architectures de pierre, Patrimoine au présent, CNMHS, éd. du CNRS, Paris, 126 p.

BAUDOUIN M. (1914) - Les cachettes et dépôts rituels de l'époque néolithique en Vendée, Revue anthropologique, p. 46-74.

BERNIER G. (1956) - Toponymie nautique de la presqu'île de Quiberon, Annales hydrographiques, $\mathrm{n}^{\circ} 1384$, Paris, $26 \mathrm{p}$.

BERSTAN R., STOTT A.W., MINNITT S., BRONK RAMSEY C., HEDGES R.E.M., EVERSHED R.P. (2008) - Direct dating of pottery from its organic residues: new precision using compound-specific carbon isotopes, Antiquity, vol. 82, p. 702-713.

BILLARD M. (1932) - Sans titre, Société archéologique et historique de Nantes et de la Loire-Inférieure, séance du 7 juin 1932, p. 113.

BORDREUIL M. (1966) - Essai sur les couples de haches en France méridionale, Congrès préhistorique de France, Ajaccio, 1966, p. 280288.

BOUJOT C., CASSEN S. (1992) - Le développement des premières architectures funéraires monumentales en France occidentale, Paysans et bâtisseurs. L'émergence du Néolithique atlantique et les origines du mégalithisme, Actes du XVII colloque interrégional sur le Néolithique, Vannes, 29-31 octobre 1990, Revue archéologique de l'Ouest, suppl. $\mathrm{n}^{\circ} 5$, p. 195-211.

BOUJOT C., CASSEN S. (1997) - Néolithisation et monumentalité funéraire : explorations du tertre de Lannec er Gadouer à Erdeven
(Morbihan, France), in A.A. Rodriguez Casal dir., O Neolitico atlantico e as orixes do Megalitismo, Actas do coloquio internacional, Santiago de Compostela, 1996, UISPP, Universidad de Santiago de Compostela, p. 211-232.

BOUJOT C., CASSEN S. (2000) - Explorations du tertre de Lannec er Gadouer. Les fouilles de 1993 à 1997, in S. Cassen dir. Eléments d'architecture (Exploration d'un tertre funéraire à Lannec er Gadouer, Erdeven, Morbihan. Constructions et reconstructions dans le Néolithique morbihannais. Propositions pour une lecture symbolique), Association Publications chauvinoises, Mémoire 19, Chauvigny, p. 29-91.

BOUJOT C., CASSEN S., VAQUERO LASTRES J. (1995) - Ideas de tierra, Congresso de Arqueologia Péninsular, Actas VI, Porto, 1993, Sociedade portuguesa de antropologia e etnologia, 2, Porto, p. 169-191.

BOUJOT C., CASSEN S., VAQUERO LASTRES J. (1998) - Some abstraction for a practical subject: the neolithization of western France as seen through funeral architecture data, Cambridge Archaeological Journal, vol. 8 (2), p. 193-206.

BOUJOT C., CASSEN S., DEFAIX J. (2000) - La pierre décorée du caveau et les gravures régionales nouvellement découvertes, in S. Cassen dir., Eléments d'architecture (Exploration d'un tertre funéraire à Lannec er Gadouer, Erdeven, Morbihan. Constructions et reconstructions dans le Néolithique morbihannais. Propositions pour une lecture symbolique), Association Publications chauvinoises, Mémoire 19, Chauvigny, p. 279-298.

CASSEN S. (1991) - Les débuts du IV millénaire en Centre-Ouest : l'hypothèse du Matignons ancien, Identité du Chasséen, Actes du colloque international, Nemours, 1989, Mémoires du musée de Préhistoire d'Île-de-France, ${ }^{\circ}$ 4, APRAIF, Nemours, p. 111-120.

CASSEN S. (1993) - Material culture and chronology of the Middle Neolithic of western France, Oxford Journal of Archaeology, vol. 12, 2, p. 197-208. 
CASSEN S. (2000a) - Architecture du tombeau, équipement mortuaire, décor céramique et art gravé du V $V^{\mathrm{e}}$ millénaire en Morbihan. À la recherche d'une cosmogonie des premières sociétés agricoles de l'Europe occidentale, Pré-historia recente da Peninsula ibérica, Actas do $3^{\circ}$ Congresso de Arqueologia Peninsular, Vila Real, 1999, vol. IV, ADECAP, Porto, p. 447-479.

CASSEN S. (2000b) - Les galets celtiformes, in S. Cassen dir., Éléments d'architecture (Exploration d'un tertre funéraire à Lannec er Gadouer, Erdeven, Morbihan. Constructions et reconstructions dans le Néolithique morbihannais. Propositions pour une lecture symbolique), Association Publications chauvinoises, Mémoire 19, Chauvigny, p. 123-128.

CASSEN S. (2000c) - La fabrication du sel. Une hypothèse fonctionnelle pour la forme céramique du caveau de Lannec er Gadouer, in S. Cassen dir., Éléments d'architecture (Exploration d'un tertre funéraire à Lannec er Gadouer, Erdeven, Morbihan. Constructions et reconstructions dans le Néolithique morbihannais. Propositions pour une lecture symbolique), Association Publications chauvinoises, Mémoire 19 Chauvigny, p. 249-265.

CASSEN S. (2000d) - La tradition céramique Castellic, in S. Cassen dir., Eléments d'architecture (Exploration d'un tertre funéraire à Lannec er Gadouer, Erdeven, Morbihan. Constructions et reconstructions dans le Néolithique morbihannais. Propositions pour une lecture symbolique), Association Publications chauvinoises, Mémoire 19, Chauvigny, p. 435-460.

CASSEN S. (2003) - Importer, imiter, inspirer? Objets-signes centreeuropéens dans le Néolithique armoricain, L'Anthropologie, t. 107, p. $255-270$.

CASSEN S. (2005) - Pigeon-Raven, Snake and Sperm whale, magical objects and domestic horned. The division of the world during the Early neo-Neolithic of western France, Symbols and Symbolism, 11th Neolithic Seminar, Ljubljana (Slovenie), 2004, Documenta Praehistorica, vol. XXXII, p. 197-204.

CASSEN S. (2007) - Le Mané Lud en images. Interprétation de signes gravés sur les parois d'une tombe à couloir néolithique (Locmariaquer, Morbihan), Gallia Préhistoire, t. 49, p. 197-258.

CASSEN S. (à paraître) - Exercice de stèle. Une archéologie des pierres dressées, Autour de la Table. Explorations archéologiques et discours savants sur des architectures néolithiques à Locmariaquer, Morbihan (Table des Marchand et Grand Menhir), Actes du colloque international, Vannes (Morbihan), 5-7 octobre 2007, université de Bretagne-sud, campus Le Tohannic.

CASSEN S., PÉTREQUIN P. (1999) - La chronologie des haches polies dites de prestige dans la moitié ouest de la France, European Journal of Archaeology, vol. 2 (1), p. 7-33.

CASSEN S., VAQUERO LASTRES J. (2000) - La forme d'une chose, in S. Cassen dir., Éléments d'architecture (Exploration d'un tertre funéraire à Lannec er Gadouer, Erdeven, Morbihan. Constructions et reconstructions dans le Néolithique morbihannais. Propositions pour une lecture symbolique), Association Publications chauvinoises, Mémoire 19, Chauvigny, p. 611-656.

CASSEN S., VAQUERO LASTRES J. (2003a) - Le désir médusé, in J. Guilaine dir., Expressions symboliques, manifestations artistiques du Néolithique et de la Protohistoire, Séminaires du Collège de France, éd. Errance, Paris, p. 91-118.

CASSEN S., VAQUERO LASTRES J. (2003b) - Les Marches du Palais Recherches archéologiques sur les alignements de stèles et tertres funéraires néolithiques autour de la baie de Quiberon, éd. du laboratoire de Préhistoire, université de Nantes, 155 p.

CASSEN S., VAQUERO LASTRES J. (2004) - Fabulous Things, Iberian Journal of Archaeology, vol. 6, p. 7-48.

CASSEN S., AUDREN C., HINGUANT S., LANNUZEL G., MARCHAND G. (1998) - L'habitat Villeneuve-Saint-Germain du Haut Mée, Saint-Étienne-en-Coglès, Ille-et-Vilaine, Bulletin de la Société préhistorique française, t. $95, \mathrm{n}^{\circ} 1$, p. 41-76.

CASSEN S., LABRIFFE P.A. de, MENANTEAU L. (2004) - Sels de mer, sels de terre. Indices et preuves de fabrication du sel sur les rivages de l'Europe occidentale, du Ve au $\mathrm{III}^{\mathrm{e}}$ millénaire, Cuadernos de Arqueologia, $\mathrm{n}^{\circ}$ 12, Universidad de Navarra, p. 9-49.
CASSEN S., TORGUNAKOV W.M. PÉTREQUIN P., LASNIER B. (2006) - Stèles en montagnes et exploitation de roches vertes en Sibérie méridionale (Taskyl, Khakassie, Russie), Journée Civilisations atlantiques et archéosciences, Laboratoire d'archéosciences, Rennes, p. $13-18$.

CASSEN S., BOUJOT C., ERRERA M., MARGUERIE D., MENIER D. PAILLER Y., PÉTREQUIN P., POIRIER S., VEYRAT E., VIGIER E (2008) - Discovery of an underwater deposit of Neolithic polished axeheads and a submerged stone alignment at Petit Rohu near SaintPierre-Quiberon (Morbihan, France), Antiquity, vol. 82, Issue 316. http://www.antiquity.ac.uk/ProjGall/cassen/index.html

CLOSMADEUC G. de (1868) - Les fouilles et les découvertes récentes de M. l'abbé Collet, vicaire de St-Pierre-Quiberon, Bull. Soc. polym. Morbihan, p. 171-175.

CLOSMADEUC G. de (1873) - Les Celtae ou haches de pierre des dolmens armoricains, Bull. Soc. polym. Morbihan, p. 21-49.

CLOSMADEUC G. de (1892) - Fouilles et découvertes récentes de coffres de pierre à Quiberon, Bull. Soc. polym. Morbihan, p. 123128.

COLES J., ORME B., BISHOP A.C., WOOLEY A.R. (1974) - A jade axe from the Somerset Levels, Antiquity, vol. XLVIII (191), p. 216220 .

COTTE V. (1924) - Documents sur la Préhistoire de Provence, éd. Dragon, Aix-en-Provence.

DELALANDE C., JOLY C., VISSET L. (2004) - Évolution du paysage végétal insulaire d'Hoëdic (Morbihan) du Néolithique moyen à la période contemporaine, Bulletin de l'AMARAI, n 17, p. 17-31.

DESMAZIÈRES O. (1925) - Inventaire des haches de pierre polie de Maine-et-Loire et relevés des polissoirs de la vallée de la Loire et de son lit, Société d'études scientifiques d'Angers, Angers, rééd. 1935.

DOMÍNGUEZ-BELLA S., CALADO D., CARDOSO J. L., CLOP X., TARRIÑO A. (2004) - Raw materials in the Neolithic-Aeneolithic of the Iberian peninsula, Slovak Geological Magazine, 1-2/2004, p. $17-$ 42 .

DURAND S. (1960) - Le Tertiaire de Bretagne. Étude stratigraphique, sédimentologique et tectonique, Mem. Soc. géol. mineral. Bretagne, Rennes, 387 p.

ERNAULT E. (1919) - Dictionnaire breton-français du dialecte de Vannes, Brud nevez, Emgleo Breiz, Brest, 2000.

ERRERA M., PÉTREQUIN P., PÉTREQUIN A.-M., CASSEN S., CROUTSCH C. (2007) - Contribution de la spectroradiométrie à la compréhension des transferts longue-distance des lames de hache au Néolithique, Bulletin de la Société tournaisienne de géologie, Préhistoire et archéologie, t. X (4), p. 101-142.

GAILLARD F. (1892a) - Le menhir et le dolmen de Roc'h Priol à Quiberon, Bulletins et Mémoires de la Société d'anthropologie de Paris, vol. $3, \mathrm{n}^{\circ} 1$, p. 71-73.

GAILLARD F. (1892b) - Inventaire avec cartes des monuments mégalithiques du Morbihan dans le périmètre des acquisitions de l'Etat dans les cantons de Quiberon, Belz et Locmariaquer, Revue des sciences naturelles de l'Ouest, $\mathrm{t}$. II, $\mathrm{n}^{\circ}$ 4, p. 404-420.

GAILLARD F. (1897) - Le dolmen du Mané Hui à Kerléarec en Carnac, Bull. Soc. d'anthropo. de Paris, t. XVII, p. 34-38.

GALLES R. (1879) - Fouille du mont Saint-Michel en Carnac faites en septembre 1862, Imp. Galles, Vannes.

GAUDIN L. (2004) - Transformations spatiotemporelles de la végétation du Nord-Ouest de la France depuis la fin de la dernière glaciation. Reconstitutions paléopaysagères, thèse de doctorat, mention : Archéologie et Archéométrie, université de Rennes 1, UFR Structure et propriétés de la matière.

GHESQUIÈRE E., MARCIGNY C., CARPENTIER V., avec la coll. de DURAND J., GIAZZON D. (2001) - Témoins d'occupation domestique du Néolithique ancien à Ponts/Plomb «le Champ Hardy» (Manche), Revue archéologique de l'Ouest, t. 18, p. 5-12. 
GRAU BITTERLI M.H., JOYE C. (2007) - Les deux structures excavées de Bevaix/Treytel-A Sugiez (Neuchâtel, Suisse) : produire des outils en contexte mégalithique, in M. Besse dir., Sociétés néolithiques. Des faits archéologiques aux fonctionnements socioéconomiques, Actes du $27^{\circ}$ colloque interrégional sur le Néolithique, Neuchâtel, 1 et 2 octobre 2005, Cahiers d'archéologie romande, $\mathrm{n}^{\circ} 108$, p. 423-429.

GRUET M. (1967) - Inventaire des mégalithes de la France : Maine-etLoire, $1^{\text {er }}$ suppl. à Gallia Préhistoire, éd. du CNRS, Paris.

HERBAUT F. (2000) - Les haches carnacéennes, in S. Cassen dir., Eléments d'architecture (Exploration d'un tertre funéraire à Lannec er Gadouer, Erdeven, Morbihan. Constructions et reconstructions dans le Néolithique morbihannais. Propositions pour une lecture symbolique), Association Publications chauvinoises, Mémoire 19, Chauvigny, p. 387-396

HERBAUT F., PAILLER Y. (2000) - Les anneaux en pierre dans le Massif armoricain, in S. Cassen dir., Éléments d'architecture (Exploration d'un tertre funéraire à Lannec er Gadouer, Erdeven, Morbihan. Constructions et reconstructions dans le Néolithique morbihannais. Propositions pour une lecture symbolique), Association Publications chauvinoises, Mémoire 19, Chauvigny, p. 353-385.

JOUSSAUME R. (2002) - Motif serpentiforme sur le menhir de la Bretellière à Saint-Macaire-en-Mauges (Maine-et-Loire), Groupe vendéen d'études préhistoriques, $\mathrm{n}^{\circ} 38$, p. 13-26.

JOUSSAUME R., RAUX P. (2006) - Sculpture serpentiforme sur le menhir de la Bretellière à Saint-Macaire-en-Mauges (Maine-et-Loire, France), in L. Laporte, R. Joussaume et C. Scarre dir., Origine et développement du mégalithisme de l'Europe de l'Ouest, musée des tumulus de Bougon, p. 727-730.

KENDRICK T.D. (1928) - The Bailiwick of Guernesey. The archaeology of the Channel islands, vol. I, Methuen and Co. Itd., London, 273 p.

LARGE J.-M. (2008) - Des pierres parlent : l'apport de la fouille de l'alignement du Douet à Hoëdic (Morbihan), Melvan, La revue des deux îles, $\mathrm{n}^{\circ} 5$, p. 10-29.

LARSONNEUR C. (1977) - La cartographie des dépôts meubles sur le plateau continental français : méthode mise au point et utilisée en Manche, J. rech. océanogr., vol. 212, p. 33-39.

LAVENOT abbé (1888) - Les îles d'Hoëdic et Houat et la presqu'île de Quiberon. Étude géographique et archéologique (suite), Bull. Soc. polym. Morbihan, t. 38, p. 106-134.

LE QUELLEC J.-M. (1984) - Hache polie et herminette en jadéite trouvées à Saint-Rémy-en-Mauges (Maine-et-Loire), Andes, $\mathrm{n}^{\circ} 1$, p. 11-15.

LE ROUX C.-T. (1985) - Gavrinis et les îles du Morbihan, Guides archéologiques de la France, ministère de la Culture, Paris.

LE ROUZIC Z. (1927) - Dépôts rituels de haches en pierre polie découverts dans la région de Carnac, Bulletin de la Société préhistorique française, t. XXIV, p. 156-160.

LE ROUZIC Z. (1930) - Carnac. Restaurations faites dans la région. Les cromlechs de Er Lannic, commune d'Arzon, de 1923 à 1926, impr. Lafolye et J. de Lamarzelle, Vannes.

LE ROUZIC Z. (1965) - Inventaire des monuments mégalithiques de la région de Carnac, Bull. Soc. polym. Morbihan, Vannes.

LE ROUZIC Z., PÉQUART M., PÉQUART S.-J. (1922) - Carnac. Fouilles faites dans la région. Campagne 1921, imp. Berger-Levrault, Nancy-Paris-Strasbourg.

LISLE DU DRENEUC P. de (1882) - Dictionnaire archéologique de la Loire-Inférieure : époques celtique, gauloise et gallo-romaine, Bull. Soc. archéo. de Nantes et de la Loire-Inférieure, t. 21, p. 93-176.

LISLE DU DRENEUC P. de (1903) - Catalogue de la collection archéologique de G. de Lisle du Dreneuc et P. de Lisle du Dreneuc 1903, Bretagne Coll. archéologique, imp. Moderne, Nantes.

LUKIS J.W. (1848) - Gavr'Innis, The Journal of the British Archaeological Association, vol. 3, p. 269-279.
MAHÉ C. (1825) - Essai sur les Antiquités du département du Morbihan, impr. Galles, Vannes.

MARIONNEAU C. (1863) - Notes d'excursions archéologiques dans le canton de Vertou (Loire-Inférieure), éd. A. Guéraud, Nantes, $17 \mathrm{p}$.

MARSILLE L. (1911) - Sur quelques sédiments clastiques et organiques de la baie de Quiberon, Bulletin de la Société polymathique du Morbihan, p. 22-224.

MARSILLE L. (1921) - Catalogue du Bulletin de la Société polymathique du Morbihan, Société polymathique du Morbihan, Vannes.

MARSILLE L. (1927) - Anneaux-disques du Morbihan, Bulletin de la Société polymathique du Morbihan, p. 90-98.

MARSILLE L. (1930) - La variation des lignes des rivages armoricains. La formation du Morbihan, Bulletin de la Société polymathique du Morbihan, p. 2-26.

MARSILLE L. (1939) - Les haches de pierre polie de la presqu'île de Rhuys (Morbihan). La découverte de Largueven en Saint-Gildas, Bulletin de la Société polymathique du Morbihan, p. 69-89.

MENIER D. (2004) - Morphologie et remplissage des vallées fossiles sud-armoricaines : apport de la stratigraphie sismique, doctorat de l'université de Bretagne-sud, mémoires Géosciences, n 110, Rennes, $202 \mathrm{p}$.

MENIER D., REYNAUD J.-Y., PROUST J.-N., GUILLOCHEAU F, GUENNOC P., TESSIER B., BONNET S., GOUBERT E. (2006) Inherited fault control on the drainage pattern and infilling sequences of late glacial incised valleys, SE coast of Brittany, France, Incised Valleys in Time and Space, SEPM (Society for sedimentary Geology), Special Publication $\mathrm{n}^{\circ} 85$, p. 37-55.

MENIER D., SCALLIET F., PROUST J.-N, CASSEN S. (à paraître) - Contexte géomorphologique et paléoenvironnemental en Bretagne-sud à l'Holocène, in $\mathrm{S}$. Cassen dir., Autour de la Table. Explorations archéologiques et discours savants sur une architecture néolithique restaurée à Locmariaquer, Morbihan (Table des Marchand et Grand Menhir), Actes du colloque international, Vannes, Morbihan, 5-7 octobre 2007, université de Bretagne-sud, campus Le Tohannic.

MORTILLET P. de (1907) - Les anneaux robenhausiens en pierre, Congrès préhistorique de France, p. 370-388.

MORZADEC-KERFOURN M.-T. (1974) - Variations de la ligne de rivage armoricaine au Quaternaire, Mémoires de la Société géologique et minéralogique de Bretagne, $\mathrm{n}^{\circ}$ 17, p. 1-208.

PAILLER Y. (2005) - Le sciage de la fibrolite en Armorique : approche technique, implications culturelles et symboliques, in G. Marchand et A. Tresset dir., Unité et diversité des processus de néolithisation sur la façade atlantique de l'Europe ( $7^{e}-4^{e}$ millénaire avant $J_{-}-C$.) Mémoire 36 de la Société préhistorique française, p. 225-243.

PAILLER Y. (2007) - Des dernières industries à trapèzes à l'affirmation du Néolithique en Bretagne occidentale (5500-3500 av. J.-C.), British Archaeological Reports, International Series, 1648, Oxford, $340 \mathrm{p}$.

PATTE É. (1954) - Les pierres de foudre dans le temps et l'espace, Librairie orientaliste Paul Geuthner, Paris.

PÉTREQUIN P., CASSEN S., CROUTSCH C., WELLER O. (1997) Haches alpines et haches carnacéennes dans l'Europe du V' millénaire, Notae Praehistoricae, t. 17, p. 135-150.

PÉTREQUIN P., CROUTSCH C., CASSEN S. (1998) - À propos du dépôt de La Bégude : haches alpines et haches carnacéennes pendant le $\mathrm{V}^{\mathbb{}}$ millénaire, Bulletin de la Société préhistorique française, t. 95, $\mathrm{n}^{\circ} 2$, p. 239-254.

PÉTREQUIN P., CASSEN S., CROUTSCH C., ERRERA M. (2002) La valorisation sociale des longues haches dans l'Europe néolithique, in J. Guilaine dir., Matériaux, productions, circulations du Néolithique à l'Âge du bronze, Séminaire du Collège de France, éd. Errance, Paris, p. 67-98. 
PÉTREQUIN P., ERRERA M., CASSEN S., CROUTSCH C. (2003) De la pétrographie aux approches sociales : la circulation des grandes haches alpines en Europe occidentale pendant le Néolithique, Table ronde d'Aurillac, 20-22 juin 2002, Préhistoire du Sud-Ouest, 5, p. 253275 .

PÉTREQUIN P., ERRERA M., CASSEN S., BILLAND G., COLAS C., MARÉCHAL D., PRODÉO F., VANGEE F. (2005a) - Des Alpes italiennes à l'Atlantique au Ve millénaire, les quatre grandes haches polies de Vendeuil et Maizy (Aisne), Brenouille (Oise), Hommage à C. Poтmepuy, Revue archéologique de Picardie, nº spécial 22, p. 75 104.

PÉTREQUIN P., PÉTREQUIN A.-M., ERRERA M., CASSEN S., CROUTSCH C., KLASSEN L., ROSSY M., GARIBALDI P., ISETTI E., ROSSI G., DELCARO D. (2005b) - Voltri, Viso et Valais. Beigua, Monviso e Valais. All'origine delle grandi asce legivate di origine alpina in Europa occidentale durante il V millennio, Materie prime e scambi nella Preistoria italiana, XXXIX Riunione scientifica dell'Istituto Italiano di Preistoria e Protostoria, Firenze, 25-27 novembre 2004, Revista di Scienze Preistoriche, vol. LV, p. 265-322

PÉTREQUIN P. CASSEN S., CROUTSCH C. (2006a) - Imitation ou convergence : les haches néolithiques à talon perforé au nord-oues des Alpes, Artisanats, sociétés et civilisations. Mélanges J.-P. Thévenot, 24e suppl. à la Revue archéologique de l'Est, p. 163-177.

PÉTREQUIN P., PÉTREQUIN A.-M., ERRERA M., CASSEN S., CROUTSCH C. (2006b) - Complexité technique et valorisation sociale : haches polies de Nouvelle-Guinée et du Néolithique alpin, in L. Astruc, F. Bon, V. Léa, P.-Y. Milcent et S. Philibert dir., Normes techniques et pratiques sociales. De la simplicité des outillages pré-et protohistoriques, XXVII's rencontres internationales d'Archéologie et d'Histoire d'Antibes, éd. APDCA, Antibes, p. 419-433.

PÉTREQUIN P., ERRERA M., PÉTREQUIN A.-M., ALLARD P. (2006c) - The neolithic quarries of Mont Viso (Piedmont, Italy). Initial radiocarbon dates, European Journal of Archaeology, vol. 9 (1), p. 7-30.

PÉTREQUIN P., PÉTREQUIN A.-M., ERRERA M., CROUTSCH C., CASSEN S., ROSSY M. (2007) - Les carrières néolithiques de jadéitite du Monviso (Piémont, Italie), $28^{e}$ Colloque interrégional sur le Néolithique (Internéo), 1 et 2 octobre 2005, université de Neuchâtel, p. 51-68.

PIERRE J.-I. (1852) - Études sur les engrais de mer des côtes de la Basse-Normandie (Manche et Calvados), éd. Hardel, Caen.

PIET F. (1863) - Recherches topographiques, statistiques et historiques sur l'île de Noirmoutier... publiées et annotées par Jules Piet, son fils, Vve Mellinet, Nantes, XXI et $725 \mathrm{p}$.

PORT C. (1874-1876-1878) - Dictionnaire historique, géographique et biographique du Maine-et-Loire, éd. Lachaise et Dolbeau, Angers.

PROUST J.-N., MENIER D., GUILLOCHEAU F., GUENNOC P., BONNET S., ROUBY D., LE CORRE C. (2001) - Les vallées fossiles de la baie de la Vilaine : nature et évolution du prisme sédimentaire côtier du Pléistocène armoricain, Bull. Soc. géol. France, t. 172, p. 737-749.

QUERRÉ G. (à paraître) - Nature des matériaux constitutifs des objets de parure et de la céramique à la Table des Marchand, in S. Cassen dir., Autour de la Table. Explorations archéologiques et discours savants sur des architectures néolithiques à Locmariaquer, Morbihan (Table des Marchand et Grand Menhir), Actes du colloque international, Vannes (Morbihan), 5-7 octobre 2007, université de Bretagne-sud, campus Le Tohannic.

QUERRÉ G., HERBAULT F., CALLIGARO T. (2008) - Transport of Neolithic variscites demonstrated by PIXE analysis, X-Ray Spectrom, vol. 37, p. 116-120

RAUX P., JOUSSAUME R. (2000) - Nouvelle gravure sur le menhir de la Bretellière à Saint-Macaire-en-Mauges dans le Maine-et-Loire, Bulletin de la Société préhistorique française, t. 97, n³ 3, p. 484486

RIALAN E. (1924) - Découvertes archéologiques faites dans le Morbihan, de 1886 à 1892, Bulletin de la Société polymathique du Morbihan, p. 29-71.
ROLLANDO Y. (1966) - Découverte de deux haches polies à Conleau (Vannes), Bulletin de la Société polymathique du Morbihan, p. 36.

SCARRE C., RAUX P. (2000) - A new decorated menhir, Antiquity, vol. $74, \mathrm{n}^{\circ} 286$, p. $757-758$

SCHULTING R., LANTING J., REIMER P. (à paraître) - New dates from Tumulus Saint-Michel, Carnac, in S. Cassen dir., Autour de la Table. Explorations archéologiques et discours savants sur des architectures néolithiques à Locmariaquer, Morbihan (Table des Marchand et Grand Menhir), Actes du colloque international, Vannes (Morbihan), 5-7 octobre 2007, université de Bretagne-sud, campus Le Tohannic.

SHEE-TWOHIG E. (1981) - The Megalithic Art of Western Europe, Clarendon Press, Oxford, $560 \mathrm{p}$

SIMONIN D., BACH S., RICHARD G., VINTROU J. (1997) - Les sépultures sous dalles de Malesherbes et la nécropole d'Orville, $L a$ culture de Cerny. Nouvelle économie, nouvelle société au Néolithique, Actes du colloque international, Nemours, 1994, Mémoires du musée de Préhistoire d'Île-de-France, $n^{\circ}$ 6, Nemours, p. 341-379.

TERS M. (1973) - Les variations du niveau marin depuis 10000 ans le long du littoral atlantique français, Le Quaternaire, géodynamique, stratigraphie et environnement, travaux français récents, $9^{e}$ congrès international de l'INQUA, Christchurch, p. 114-135.

VILLALBA M.J., EDO M., BLASCO A. (1998) - Explotacion, manufactura, distribucion y uso como bien de prestigion de la calaita en el Neolitico. El ejemplo del complejo de Can Tintorer, Minerales y Metales en la prehistoria reciente, Fundacion Duques de Soria, Universidad de Valladolid, Valladolid, p. 41-70.

VISSET L., L'HELGOUAC'H J., BERNARD J. (1996) - La tourbière submergée de la pointe de Kerpenhir à Locmariaquer (Morbihan), étude environnementale et mise en évidence de déforestations et de pratiques agricoles néolithiques, Revue archéologique de l'Ouest, t. 13 , p. $79-87$.

WENTINK K. (2008) - Crafting axes, producing meaning. Neolithic axe depositions in the northern Netherlands, Archaeological Dialogues, vol. 15 (2), p. 151-173.

Serge CASSEN

UMR 6566 (CNRS, ministère de la Culture, universités Rennes 1, Rennes 2, Nantes) LARA, université de Nantes BP 81227, 44312 Nantes Cedex 3 serge.cassen@univ-nantes.fr

Christine BOUJOT

UMR 6566 (CNRS, ministère de la Culture, universités Rennes 1, Rennes 2, Nantes)

DRAC, SRA Bretagne Avenue C. Foulon, 35700 Rennes christine.boujot@culture.gouv.fr

Michel ERRERA Musée royal de l'Afrique centrale Tervuren, Belgique michel.errera@africamuseum.be

David MENIER

EA 2219 Géarchitecture Université de Bretagne-sud Rue Yves-Mainguy, BP 573, 56017 Vannes Cedex david.menier@univ-ubs.fr 
Yvan PAILLER

Arscan (UMR 7041)

Équipe Protohistoire européenne, Nanterre yvan.pailler@club-internet.fr

Pierre PÉTREQUIN

UMR 6249, laboratoire de Chrono-environnement CNRS et université de Franche-Comté, Besançon

Dominique MARGUERIE

UMR 6566 (CNRS, ministère de la Culture, universités Rennes 1, Rennes 2, Nantes)

FR 2116 (IFR 90) CAREN «Centre armoricain de recherches en environnement» Laboratoire d'archéosciences

Université de Rennes 1, 35042 Rennes Cedex dominique.marguerie@univ-rennes1.fr

Elisabeth VEYRAT

Ministère de la Culture

Direction de l'Architecture et du patrimoine, sous-direction de l'Archéologie

Département des Recherches archéologiques subaquatiques et sous-marines Fort Saint-Jean, 13235 Marseille Cedex 02 elisabeth.veyrat@culture.gouv.fr

Emmanuelle VIGIER Musée de Carnac, 56340 Carnac e.vigier@museedecarnac.fr
Sandy POIRIER

LARA, université de Nantes BP 81227, 44312 Nantes Cedex 3

Charles DAGNEAU

ADRAMAR

ZA La Fontenelle, 35113 Domagné

Denis DÉGEZ

ADRAMAR

ZA La Fontenelle, 35113 Domagné

Thierry LORHO

DRAC, SRA Bretagne

Avenue C. Foulon, 35700 Rennes

Hervé NEVEU-DÉROTRIE

Musée départemental Dobrée

18, rue Voltaire, BP 40415 44004 Nantes Cedex 1

Christian OBELTZ

La Petite Métairie, 56340 Carnac

Florent SCALLIET

Université de Bretagne-sud Rue Yves-Mainguy, BP 573, 56017 Vannes Cedex

Yohan SPARFEL Rue du Stade, 29830 Saint-Pabu 